\title{
Direct Insolation Models
}

\section{MASTER}

Richard Bird

Roland L. Hulstrom
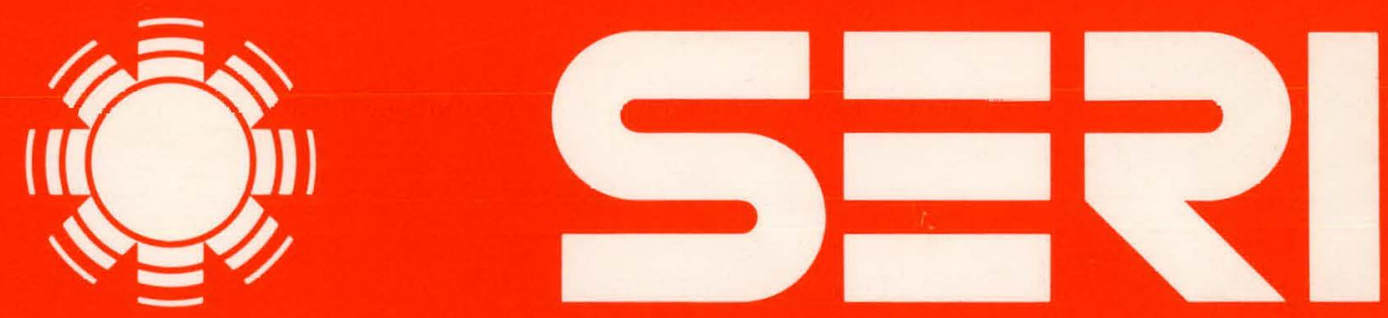

Solar Energy Research Institute

A Division of Midwest Research Institute

1536 Cole Boulevard

Golden, Colorado 80401

Operated for the

U.S. Department of Energy under Contract No. EG-77-C-01-4042 


\section{DISCLAIMER}

This report was prepared as an account of work sponsored by an agency of the United States Government. Neither the United States Government nor any agency Thereof, nor any of their employees, makes any warranty, express or implied, or assumes any legal liability or responsibility for the accuracy, completeness, or usefulness of any information, apparatus, product, or process disclosed, or represents that its use would not infringe privately owned rights. Reference herein to any specific commercial product, process, or service by trade name, trademark, manufacturer, or otherwise does not necessarily constitute or imply its endorsement, recommendation, or favoring by the United States Government or any agency thereof. The views and opinions of authors expressed herein do not necessarily state or reflect those of the United States Government or any agency thereof. 


\section{DISCLAIMER}

Portions of this document may be illegible in electronic image products. Images are produced from the best available original document. 


\author{
Printed in the United States of America \\ Available from: \\ National Technical Information Service \\ U.S. Department of Commerce \\ 5285 Port Royal Road \\ Springfield, VA 22161 \\ Price: \\ Microfiche $\$ 3.00$ \\ Printed Copy $\$ 5.25 \%$, is
}

\begin{abstract}
NOTICE
This report was prepared as an account of work sponsored by the United States Government. Neither the United States nor the United States Department of Energy, nor any of their employees, nor any of their contractors, subcontractors, or their employees, makes any warranty, express or implied, or assumes any legal liability or responsibility for the accuracy, completeness or usefulness of any information, apparatus, product or process disclosed, or represents that its use would not infringe privately owned rights.
\end{abstract}


SER I /TR-335-344

UC CATEGORY: UC-59,61,62,63

DIRECT INSOLATION MODELS

RI CHARD BIRD

ROLAND L. HULSTROM

JANUARY 1980

PREPARED UNDER TASK No. 3623.01

\section{Solar Energy Research Institute}

1536 Cole Boulevard

Golden, Colorado 80401

A Division of Midwest Research Institute

Prepared for the

U.S. Department of Energy

Contract No. EG $\cdot 77 \cdot C \cdot 01 \cdot 4042$ 
THIS PAGE

\section{WAS INTENTIONALLY LEFT BLANK}




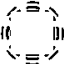

\section{FOREWORD}

This report documents work performed by the SERI Energy Resource Assessment Branch for the Division of Solar Energy Technology of the U.S. Department of Energy. The report compares several simple direct insolation models with a rigorous solar transmission model and describes an improved, simple, direct insolation model.

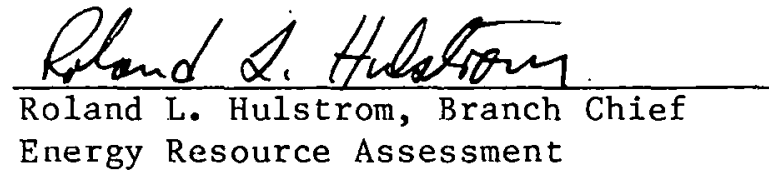

Approved for:

SOLAR ENERGY RESEARCH INSTITUTE
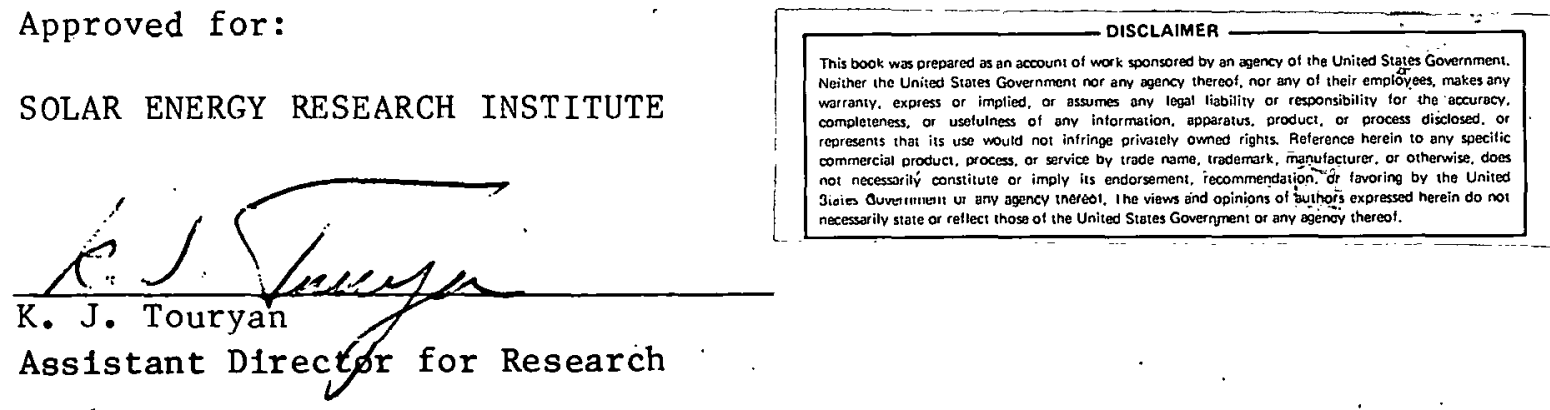
THIS PAGE

\section{WAS INTENTIONALLY \\ LEFT BLANK}


TABLE OF CONTENTS

$\underline{\text { Page }}$

1.0 Introduction..................................... 1

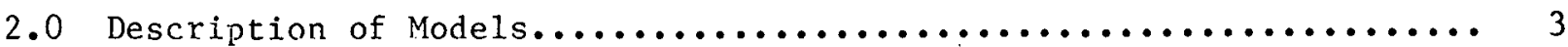

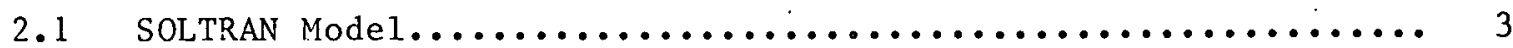

2.2 Atwater and Ball Model........................... 4

2.3 Hoyt Model................................... 5

2.4 Lacis and Hansen Model........................... 7

2.5 Machta Mode1................................. 7

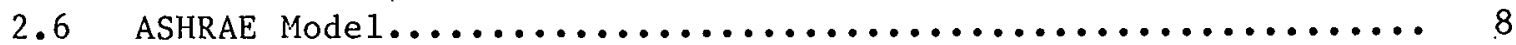

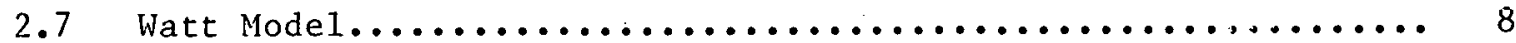

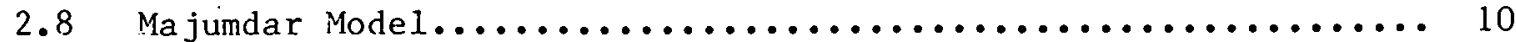

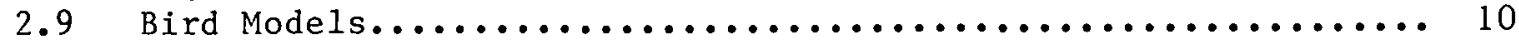

2.10 Additional Models and Other Considerations............... 12

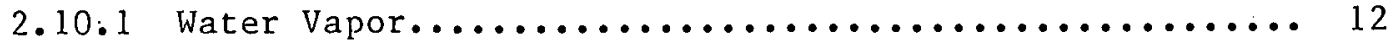

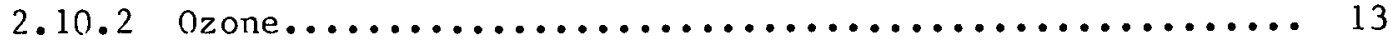

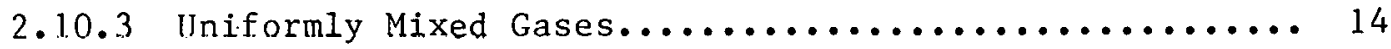

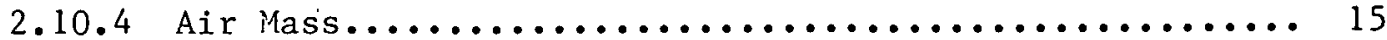

2.10 .5 Simple Transport Equatiori.................... 16

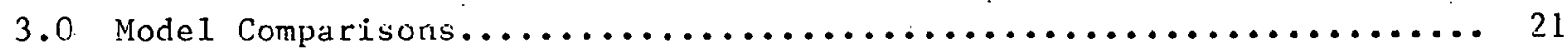

4.0 Summary and Conclusions................................ 39

5.0 References..................................... 43

Appendix. Tabulated Model Data........................... A1 


\section{THIS PAGE \\ WAS INTENTIONALLY \\ LEFT BLANK}


3-1 Transmittance versus Secant of Solar Zenith Angle for Midlatitude Summer Model.......................... 22

3-2 Transmittance versus Secant of Solar Zenith Angle for Subarctic Winter Model.......................... 23

3-3 Ozone Absorptance versus Solar Zenith Angle for

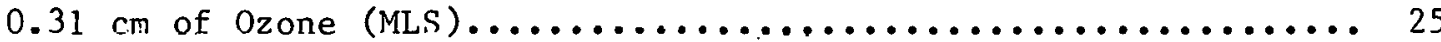

3-4 Ozone Absorptance versus Solar Zenith Angle for

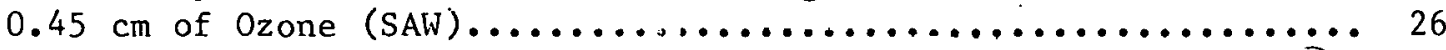

3-5 Absorptance versus Solar Zenith Angle for $2.93 \mathrm{~cm}$ of Water Vapor (MLS)........................ 27

3-6 Absorptance versus Solar Zenith Angle for

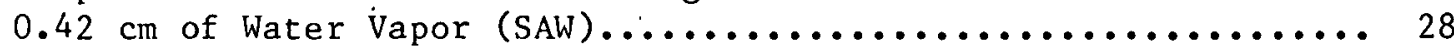

3-7 Transmittance versus Solar Zentth Angle for All Molecular Effects Except $\mathrm{H}_{2} \mathrm{O}$ Absorption (MLS)............. 29

3-8 Iransmittance versus Solar Zenith Angle for Al1 Molecular Effects Except $\mathrm{H}_{2} \mathrm{O}$ Absorption (SAW)............ 30

3-9 Aerosol Transmittance versus Solar Zenith Angle for 5-km Visibility Aerosol............................ 31

3-10 Aerosol Transmittance versus Solar Zenith Angle for $23-\mathrm{km}$ Visibility Aerosol............................ 32

3-11 Solar Irradiance versus Solar Zenith Angle,

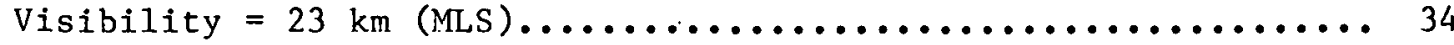

3-12 Solar Irradiance versus Solar Zenith Angle, - Visibility $=5 \mathrm{~km}$ (MLS) $\ldots \ldots \ldots \ldots \ldots \ldots \ldots \ldots \ldots \ldots \ldots \ldots \ldots \ldots \ldots$

3-13 Solar Irradiance versus Solar Zenith Angle, Visibility $=23 \mathrm{~km}$ (SAW). 


\section{THIS PAGE}

\section{WAS INTENTIONALLY \\ LEFT BLANK}




\section{LIST OF TABLES}

$\underline{\text { Page }}$

2-1 Sources of Data for Construction of Models................... 14

2-2 Comparisons of Direct Normal Irradiance for Different Forms of the Transport Equation Using Bird Models and SOLTRAN............. 17

2-3 Comparisons of Direct Normal Irradiance for Different Forms of the Transport Equation Using Bird Models and SOLTRAN............. 18

A-1 Tabulated Data for the Midlatitude Summer Atmosphere

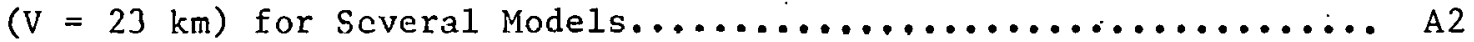

A-2 Tabulated Data for the Midlatitude Summer Atmosphere

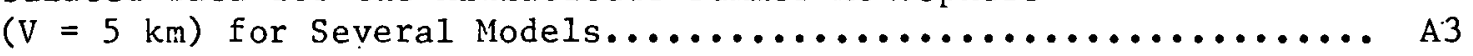

A-3 Tabulated Data for the Subarctic Winter Atmosphere

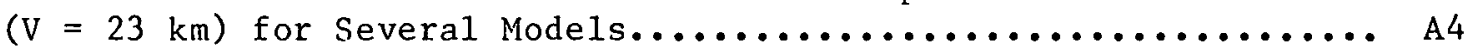

A-4 Tabulated Data for the Subarctic Winter Atmosphere ( $\mathrm{V}=5 \mathrm{~km})$ for Several Models................................. A5 . 
SECTION $\cdot 1.0$

INTRODUCTION

Solar energy (insolation) conversion systems are different from systems based on other sources of energy, because the energy source is subject to varying meteorological conditions. As a result, reliable insolation data are required at each site of interest to design a solar energy system. Historical data have been collected by the National Weather Service (NWS) on a very limited basis at 26 locations throughout the United States, and data are currently being collected at 38 locations. Because of the small number of stations in this network and the variability of insolation, it is essential to have accurate models to predict insolation at other locations. The accuracy of these models and experimental data affects the design, performance, and economics of solar systems.

Numerous simple insolation models have been produced by different investigators over the past half century. The goal of these models has been to provide an uncomplicated estimation of the available insolation. These models, by very different methods, account for the influence of each atmospheric constituent on solar radiation. This, in turn, leads to confusion and questions of validity from prospective users.

This study compares several of the more recent models of the direct component of the insolation for clear sky conditions. The comparison includes seven simple models and one rigorous model that is a basis for determining. accuracy. The results of the comparisons are then used to formulate two simple. models of differing complexity. The most useful formalisms of present models have been incorporated into the new models.

The criteria for evaluating and formulating models are simplicity, accuracy, and the ability to use readily available meteorological data.

In the future, a similar analysis of models for global and diffuse insolation is planned. Simple global and diffuse models will be compared with a rigorous model that uses Monte Carlo techniques. Additional comparisons are planned, with very carefully taken experimental data for both direct and diffuse insolation components. As many meteorological measurements as can reasonably be taken will be included with these data.

The goal of this work is to produce a well-documented global insolation model that includes the direct and diffuse clear sky insolation as well as cloud-and ground-reflected insolation. This report is the first step toward achieving that goal. 
SEPI楼

\section{.}


SECTION 2.0

DESCRIPTION OF MODELS

A rigorous atmospheric transmission model has served as a basis for comparing the accuracy of simple empirical models. The next few sections present a description of the rigorous model and the mathematical expressions that form the simplified models.

\subsection{SOLTRAN MODEL}

The rigorous mode1, called SOLTRAN, was constructed from the LOWTRAN [1-3] atmospheric transmission model produced by the Air Force Geophysics Laboratory and the extraterrestrial solar spectrum of Thekaekara [4].

The LOWTRAN model has evolved through a series of updates and continues to be improved with new data and computational capabilities. In this model, a layered atmosphere is constructed between sea level and $100-\mathrm{km}$ altitude by defining atmospheric parameters at 33 levels within the atmosphere. The actual layer heights at which atmospheric parameters are defined are: sea level $(0.0 \mathrm{~km})$ to $25-\mathrm{km}$ altitude in $1.0-\mathrm{km}$ intervals, 25 to $50 \mathrm{~km}$ in $5-\mathrm{km}$ intervals, and at $70 \mathrm{~km}$ and $100 \mathrm{~km}$, respectively. At each of these 33 altitudes the following quantities are defined: temperature, pressure, molecular density, water vapor density, ozone density, and aerosol extinction and absorption coefficients. A complete description of the standard model atmospheres incorporated in this code is given by McClatchey et al. [5].

The absorption coefficients of water vapor, ozone, and the combined effects of the uniformly mixed gases $\left(\mathrm{CO}_{2}, \mathrm{~N}_{2} \mathrm{O}, \mathrm{CH}_{4}, \mathrm{CO}, \mathrm{N}_{2}\right.$, and $\left.\mathrm{O}_{2}\right)$ are stored in the code at $5-\mathrm{cm}^{-1}$ wavenumber intervals with a resolution of $20 \mathrm{~cm}^{-1}$. The average transmittance over a $20-\mathrm{cm}^{-1}$ interval as a result of molecular absorption is calculated by using a band absorption model. The band absorption model is based on recent laboratory measurements complemented by using available theoretical molecular line constants in line-by-line transmittance calculations.

The effects of earth curvature and atmospheric refraction are included in this model. The results of earth curvature become important along paths that are at angles greater than $60^{\circ}$ from the zenith, and refractive effects then dominate at zenith angles greater than $80^{\circ}$.

The scattering and absorption effects of atmospheric aerosols (dust, haze, and other suspended materials) are stored in the code in extinction and absorption coefficients as a function of wavelength. These coefficients were produced by a MIE code for defined particle size distributions and complex indices of refraction. Four aerosol models are available, representing rural, urban, maritime, and tropospheric conditions.

A user can choose any one of six. standard atmospheric models incorporated in the code or can construct his own atmosphere by using a combination of parameters from the standard models or by incroducing radiusunde data. 
Some of the outputs of the LOWTRAN code include the total transmittance; the transmittance of $\mathrm{H}_{2} \mathrm{O}, \mathrm{O}_{3}$, and the uniformly mixed gases; and aerosol transmittance at each wavelength value specified. In the SOLTRAN model these transmittance values are multiplied by Thekaekara's corresponding extraterrestrial solar irradiance at each wavelength of interest. A sum (integration) of the results of these individual multiplications is then performed over the spectral interval of interest to produce a value of the broadband terrestrial direct beam irradiance. The current version of SOLTRAN is limited to a spectral region between 0.25 and $3.125 \mu \mathrm{m}$ because of a limited extraterrestrial solar spectral data file.

\subsection{ATWATFR AND RAIL MONEL}

A model for the direct solar insolation was published recently by Atwater and Bal1 [6]. This is a modification of an earlier model published by Atwater and Brown [7], which also includes a diffuse insolation formalism and the effert of clouds, neither of which are discussed here.

The equation for the direct insolation on a horizontal surface is given by:

$$
I=I_{0}(\cos Z)\left[T_{M}-a_{W}\right] T_{A},
$$

where

$$
\begin{aligned}
& \mathrm{I}_{0}=\text { extraterrestrial solar irradiance, } \\
& \mathrm{Z}=\text { solar zenith angle, } \\
& \mathrm{T}_{\mathrm{M}}=\text { transmittance tor all molecular effects except water vapor ab- } \\
& \mathrm{a}_{\mathrm{w}}=\text { absorptance of water vapor, } \\
& \mathrm{T}_{A}=\text { transmittance of aerosols. }
\end{aligned}
$$

The mathematical expressions for the transmittance, absorptance, and air mass $M$, are given by:

$$
\begin{gathered}
\mathrm{T}_{M}=1.041-0.15\left[\mathrm{M}\left(949 \times 10^{-6} \mathrm{P}+0.051\right)\right]^{0.5,}, \\
a_{w}=0.077\left(U_{W} M\right)^{0.3,} .
\end{gathered}
$$

\footnotetext{
*Atwater and Ball recently published an errata sheet in Solar Energy, Vol. 23, p. 275, changing the coefficient, 0.15, in Eq. 2 to 0.16 . This change has not been incorporated in the results presented here.
} 
iii

$$
\begin{gathered}
T_{A}=\exp \left(-\alpha M^{\prime}\right), \\
M=35 /\left[\left(1224 \cos ^{2} Z\right)+1\right]^{0.5}, \\
M^{\prime}=P \cdot M / 1013 .
\end{gathered}
$$

where

$$
\begin{aligned}
& \mathrm{U}_{\mathrm{W}}=\begin{array}{l}
\text { amount of water vapor in a vertical path through the atmosphere } \\
(\mathrm{cm}),
\end{array} \\
& \alpha=\text { total broadband optical depth of the aerosol, } \\
& \mathrm{P}=\text { surface pressure }(\mathrm{mb}) .
\end{aligned}
$$

A brief discussion of the form of Eq. 1 is given in. Paltridge and P1att [8]. The form of Eq. 2 is a slight variation of an empirical formula derived by Kastrov and discussed by Kondratyev [9]. Equation 3 is the form derived by McDonald [10], and Eq. 5 is a modification of a formula used by Rodgers for ozone and discussed by Paltridge and Platt [8].

Equation 4 is discussed in more detail by Atwater and Brown [7]. They used a MIF theory calculation to determine the value of $\alpha$, which is not the approach that would be used in a simple, user-oriented model.

Results from using this model are presented in a later section with a comparisons of other models.

\subsection{HOYT MODEL}

A model for solar global insolation that includes a model for the direct component is described by Hoyt [11]. The following equation is for the direct solar insolation on a horizontal surface:

$$
I=I_{0}(\cos z)\left(1-\sum_{i=1}^{5} a_{i}\right) T_{A S} T_{R}
$$

where $a_{i}$ represents the absorptance values for water vapor $(i=1)$, carbon dioxide $(i=2)$, ozone $(i=3)$, oxygen $(i=4)$, and aerosols $(i=5)$. The parameter $\mathrm{T}_{A S}$ is the transmittance after aerosol scattering, and $\mathrm{T}_{\mathrm{R}}$ is the transmittance after pure air, or Rayleigh, scattering. The following formulas define these parameters:

$$
\begin{aligned}
& a_{1}=0.110\left(U_{w}^{\prime}+6.31 \times 10^{-4}\right)^{0.3}-0.0121, \\
& a_{2}=0.00235\left(U_{c}^{\prime}+0.0129\right)^{0.26}-7.5 \times 10^{-4},
\end{aligned}
$$




$$
\begin{gathered}
a_{3}=0.045\left(U_{0}^{\prime}+8.34 \times 10^{-4}\right)^{0.38}-3.1 \times 10^{-3}, \\
a_{4}=7.5 \times 10^{-3}\left(\mathrm{M}^{\prime}\right)^{0.875}, \\
a_{5}=0.05[\mathrm{~g}(\mathrm{~B})]^{\mathrm{M}^{\prime},} \\
\mathrm{T}_{\mathrm{AS}}=[\mathrm{g}(\mathrm{B})]^{\mathrm{M}^{\prime}}, \\
\mathrm{T}_{\mathrm{R}}=\left[\mathrm{f}\left(\mathrm{M}^{\prime}\right)\right]^{\mathrm{M}^{\prime}},
\end{gathered}
$$

where

$$
\begin{aligned}
& U_{W}^{\prime}=\text { pressure-corrected* precipitahle water in the path }(\mathrm{cm}) \text {, } \\
& \mathrm{U}_{\mathrm{C}}^{\prime}=\text { pressure-corrected amount of carbon dioxide in the path [cm } \\
& U_{0}^{\prime}=\text { the dinount of ozone in the path ( } \mathrm{cm} \text { at STP), } \\
& M^{\prime} \quad=\text { pressure-corrected air mass, } \\
& g(\beta)=a \text { tabulated function that is related to the angstrom tur- } \\
& \text { bidity coefficient } \beta \text {, } \\
& f\left(M^{\prime}\right)=\text { a tabulated function of pressure-corrected air mass. }
\end{aligned}
$$

See Hoyt [11] for the tabular data.

Because the functions $g(B)$ and $f^{\left(M^{\prime}\right)}$ are in tabular form rather than in empirical expressions, this model is not as flexible as it could be. The use of the tables often requires interpolation between points, and the range of air masses and turbidity coefficients listed in the tables is sometimes too limited. Results of this model will be presented in a later section.

*Hoyt calculates the pressure-corrected precipitable water by multiplying the total precipitable water from radiosonde data by 0.75 in a recent report. This correction has not been made in the analysis performed here. 


\subsection{LACIS AND HANSEN MODEL}

Lacis and Hansen [12] have described a formalism for total insolation. Since they do not separate the direct and diffuse components of the insolation, their formalism cannot be considered here. However, they derived useful empirical expressions for water vapor and ozone absorption. The water vapor absorptance is expressed by

$$
a_{w}=2.9 Y\left[(1+141.5 Y)^{0.635}+5.925 Y\right]^{-1}
$$

where $Y=M U_{W}$, with $U_{w}$ being the precipitable water vapor $(\mathrm{cm})$ in a vertical path.

The expression for ozone absorptivity in the Chappuis band is given by

$$
a_{0}^{v i s}=0.02118 \times\left(1+0.042 x+0.000323 x^{2}\right)^{-1} \text {, }
$$

and for the ultraviolet band by

$$
a_{0}^{u v}=1.082 x(1+138.6 x)^{-0.805}+0.0658 x\left[1+(103.6 x)^{3}\right]^{-1}
$$

where $X=U_{0} M$ with $U_{0}$ being the amount $(\mathrm{cm})$ of ozone in a vertical path. The total ozone absorptivity is given by the sum

$$
a_{0}=a_{0}^{v i s}+a_{0}^{u v}
$$

Comparisons of the results of these expressions with other models is shown in a later section.

\subsection{MACHTA MODEL}

A simple model of global insolation has been constructed by Machta [13] in the form of graphs and a worksheet. This model is an approximate method for calculating solar insolation at a given location without the use of mathenatical expressions. A standard value of direct solar insolation is given as 887 $\mathrm{W} \mathrm{m}^{-2}$, and a standard value of diffuse insolation is given as $142.5 \mathrm{~W} \mathrm{~m}^{-2}$. These standard values are then corrected by the use of graphs and the worksheet. The corrections are made for station altitude, zenith angle, precipitable watcr, turbidity, and earth-sun distance. This method has greatest accuracy for very clear days and small zenith angles.

The graphs for making corrections are based on the very rigorous calculations of Braslau and Dave [14]. A few examples of calculatiluis using this model will be illustrated in a later section. 


\subsection{ASHRAE MODEL}

The American Society of Heating, Refrigeration and Air Conditioning Engineers, ASHRAE, publishes a simple model $[15,16]$ for estimating solar insolation at locations in the Northern Hemisphere. This method represents the solar insolation at the earth's surface, under clear sky conditions, by using

$$
I_{D N}=A e^{-B} \sec \mathrm{Z} \text {, }
$$

where

$$
\begin{aligned}
& A=\text { the "apparent" extraterrestrial solar radintion, } \\
& B=\text { the "apparent" optical attenuation coefficient, } \\
& Z=\text { the solar zenith angle. }
\end{aligned}
$$

An atmospheric clarity adjustment, $C N$, called the clearness number, is then used to multiply the direct normal insolation calculated using Eq..18. This clearness number corrects for variations in transmittance at a particular location. Values of $A, B$, and $C N$ are published by ASHRAE [15] as well as tables of solar insolation for the Northern Hemisphere [16] resulting from application of these parameter values.

$\Lambda$ thorough discussion of the origin of the ASHRAE model is presented by Hulstrom [17], and this information will not be repeated here. It is sufficient to say that Eq. 18, commonly called Beer's Law, is strictly applicable only for monochromatic radiation. If one takes the natural logarithm of Eq. 18, the result 1s:

$$
\ln I_{D N}=\ln A-B \sec Z \text {. }
$$

A plot of this expression on $a \ln I_{\mathrm{DN}}$ versus scc $Z$ axis systein results in a straight line, with $A$ the intercept of the logarithmic axis and $B$ the slnpe of the line. The vertical intercept $A$ occurs for the extrapolation. sec $Z=0.0$, which corresponds to zero air mass or the extraterrestrial incolation.

In the model comparisons given in a later section the deviations of thic model from more accurate results are indicated. Hulstrom [17] points out that the rlearues: numbers published by ASHRAE correct only for water vapor variations. Moreover, these are only average water vapor conditions, and it is shown here in a later section that variations in aerosol attenuation are normally a much more significant factor.

\subsection{WATT MODEL}

A model for global insolation has been constructed by Watt [18], based partly on the work of Moon [19]. The expression for the direct normal insolation is

$$
\mathrm{I}_{\mathrm{DN}}=\mathrm{I}_{0} \mathrm{~T}_{\text {wa }} \mathrm{T}_{\text {as }} \mathrm{T}_{0} \mathrm{~T}_{\mathrm{ws}} \mathrm{T}_{\mathrm{L}} \mathrm{T}_{\mathrm{u}} \text {, }
$$


where the transmittance functions are $\mathrm{T}_{\text {wa }}$ for water vapor absorption, $\mathrm{T}_{\text {as }}$ for dry air scattering, $\mathrm{T}_{0}$ for ozone absorption, $\mathrm{T}_{\mathrm{ws}}$ for water vapor scattering, $\mathrm{T}_{\mathrm{L}}$ for lower level aerosol absorption and scattering, and $\mathrm{T}_{\mathbf{u}}$ for upper layer aerosol absorption and scattering. These transmittance functions are defined by

$$
\begin{aligned}
& \mathrm{T}_{\text {wa }}=0.93-0.033 \log \left(\mathrm{U}_{\mathrm{w}} \mathrm{M}_{2}\right) \text {, } \\
& \mathrm{T}_{\text {as }}=10^{-0.045 \cdot\left[\left(\mathrm{P} / \mathrm{P}_{0}\right) \mathrm{M}_{1}\right]^{0.7}} \text {, } \\
& \mathrm{T}_{0}=10^{-\left(0.00 \% 1+0.01 \cdot U_{0} M_{4}\right)} \\
& \mathrm{T}_{\mathrm{wS}}=10^{-\left(0.0095 \cdot \mathrm{U}_{\mathrm{w}} \mathrm{M}_{2}\right)} \text {, } \\
& \mathrm{T}_{\mathrm{L}}{ }^{\cdots}=10^{-\tau_{\mathrm{L}} \mathrm{M}_{2}}{ }^{0.7} \text {, } \\
& T_{u}=10^{-\tau} \mathrm{u}_{3}, \\
& \tau_{L}=0.6\left(\tau_{0.5}-0.01 U_{w}-0.03\right), \\
& \tau_{\mathrm{u}}=-\mathrm{M}_{3}{ }^{-1} \log \left(\mathrm{I}_{\mathrm{obs}} / \mathrm{I}_{0}\right)-\tau_{\mathrm{L}}\left(\mathrm{M}_{2} / \mathrm{M}_{3}\right) .
\end{aligned}
$$

The parameter $P_{0}$ is the sea level pressure; $P$ is the pressure at the surface being considered; $U_{0}$ and $U_{w}$ are the amount of ozone and water vapor in $\mathrm{cm}$ in a vertical path; $\tau_{0.5}$ is the atomospheric turbidity at $0.5-\mu \mathrm{m}$ wavelength; Iobs is undefined in watt's report; and $I_{0}$ is the broadband extraterrestrial insolation. The parameters $\tau_{u}$ and $\tau_{L}$ are the upper and lower layer broadband turbidity or optical depth. $\tau_{u}$ can be taken from plots in Watt's report for past years. The $M_{i}$ are called path length modifiers by Watt, and they serve the same purpose as air mass in the previous models. These path length modifiers are equal for solar zenith angles $\leqslant 70^{\circ}$ and are equal to the secant of the solar zenith angle $(\sec Z)$. For solar zenith angles $\geqslant 70^{\circ}$, the path length modifier is defined differently for each atmospheric constituent according to the altitudes in the atmosphere between which the constituent is concentrated. A parameter $\mathrm{F}_{z i}$ is calculated using the following expression:

$$
F_{z i}-\left\{\left[\left(r / h_{i}\right) \cos z\right]^{2}+2 r / h_{i}+1\right\}^{0.5}-\left(r / h_{1}\right) \cos z
$$


where $r$ is the earth's radius $\left(6.4 \times 10^{6} \mathrm{~m}\right)$ and the $h_{i}$ are the atmospheric altitudes (heights) between which the constituent is located. If a constituent is concentrated between two altitudes, $h_{1}$ and $h_{2}$, an $F_{z 1}$ and $F_{22}$ are calculated corresponding to $h_{1}$ and $h_{2}$, respectively. The values are then used in the following expression to obtain the total path length modifier:

$$
M_{i}=\frac{h_{2} F_{z 2}-h_{1} F_{z 1}}{h_{2}-h_{1}} \text {. }
$$

The values of $h$ used for the various constituents are:

$$
\begin{array}{ll}
\text { ozone: } & \mathrm{h}_{1}=20 \mathrm{~km}, \mathrm{~h}_{2}=40 \mathrm{~km} \\
\text { dry air: } & \mathrm{h}_{1}=0 \mathrm{~km}, \mathrm{~h}_{2}=30 \mathrm{~km} . \\
\text { upper dust: } & \mathrm{h}_{1}=15 \mathrm{~km}, \mathrm{~h}_{2}=25 \mathrm{~km} \\
\text { 1.nwer dust } & \\
\text { and water vapor: } & \mathrm{h}_{1}=0 \mathrm{~km}, \mathrm{~h}_{2}=3 \mathrm{~km} .
\end{array}
$$

When the value of $h$ is equal to zero, the corresponding $F_{z}$ can be set equal to 1.0 , and $M_{i}=F_{z 2}$.

\subsection{MAJUMDAR MODEL}

A model for direct normal insolation has been ronstrurted hy Majumdar et a1. [20]. This model is for clear sky conditions and minimal aerosol content, so that the etfect of variable turbidity is not considered. A total of 161 sets of observations at three locations in India was used to arrive at the following regression equation:

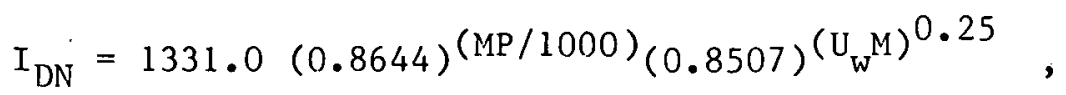

where $M$ is the air mass, $P$ is the surface pressure, and $U_{w}$ is the amount of water vapor in a vertical path.

Results generated from this model will be presented in a later section.

\subsection{BIRD MODELS}

As a result of comparing the simple models discussed in this section with the rigorous model (presented in a later section), the authors formulated two additional models. Where possible, these models used formalisms from the 
models previously presented. The expressions used were tuned to give the best least-squares fit to the SOLTRAN data. The first model used the following expression for direct normal insolation:

$$
I_{D N}=I_{0}(0.9662)\left(T_{R} T_{0} T_{u}-a_{W}\right) T_{A}
$$

where $\mathrm{T}_{\mathrm{u}}$ is the transmittance of the uniformly mixed gases $\left(\mathrm{CO}_{2}\right.$ and $\left.\mathrm{O}_{2}\right)$, and the other parameters are the same as defined earlier. The 0.9662 factor was added because the spectral interval considered with SOLTRAN was from 0.3 to $3.0 \mu \mathrm{m}$. The total irradiance in the extraterrestrial solar spectrum in this interval is $1307 \mathrm{~W} / \mathrm{m}^{2}$, whereas the Thekaekara solar constant of $1353 \mathrm{~W} / \mathrm{m}^{2}$ is used in most of the other models. The factor of 0.9662 allows one to use $\mathrm{I}_{0}=$ $1353 \mathrm{~W} / \mathrm{m}^{2}$ with the Bird Models. If a higher value of this solar constant is desired (i.e., $1377 \mathrm{~W} / \mathrm{m}^{2}$ ), it can be used without changing Eq. 32. The transinittance and absorptance equations are

$$
\begin{aligned}
& T_{R}=\exp \left[-0.0903\left(M^{\prime}\right)^{0.84}\left(1.0+M^{\prime}-\left(M^{\prime}\right)^{1.01}\right)\right] \text {, } \\
& \dot{T}_{0}=1.0-0.1611 x_{0}\left(1.0+139.48 x_{0}\right)^{-0.3035} \\
& -0.002715 x_{0}\left(1.0+0.044 x_{0}+0.0003 x_{o}^{2}\right)^{-1} \text {, } \\
& T_{u}=\exp -0.0127\left(M^{\prime}\right)^{0.26} \text {, } \\
& a_{w}=2.4959 x_{w}\left[\left(1.0+79.034 x_{w}\right)^{0.6828}+6.385 x_{w}\right]^{-1}, \\
& \mathrm{~T}_{\mathrm{A}}=\exp \left[-\tau_{A} 0.873\left(1.0+\tau_{A}-{ }^{\tau_{A}}{ }^{0.7088}\right) \mathrm{M}^{0.9108}\right], \\
& \tau_{A}=0.2758 \tau_{A}(0.38)+0.35 \tau_{A}(0.5), \\
& M=\left[\cos z+0.15(93.885-z)^{-1.25}\right]^{-1},
\end{aligned}
$$

where $M^{\prime}=M P / P_{0}, X_{0}=U_{0} M, . X_{W}=U_{W} M, T_{u}$ is the transmittance of the uniformly mixed gases, ${ }^{\tau} A$ is the broadband atmospheric turbidity, and ${ }_{A}(0.38)$ and ${ }^{2} \mathrm{~A}(0.5)$ are the atmospheric turbidity values that are measured on a regular basis by NWS at $0.38-$ and $0.5-\mu \mathrm{m}$ wavelengths, respectively. If one of the turbidity values is not available, its value can be entered as a zero in $\mathrm{Eq}$. 38. The values of $\tau(0.38)$ and $\tau(0.5)$ are obtained in practice with a turbidity meter that measures the total optical depth at each wavelength. The optical depth due to molecular scattering is then subtracted from the total 
optical depth to obtain the turbidity (or aerosol optical depth) at each wavelength. Equation 39 is a form derived by Kasten [21]. The forms of Eqs. 34 and 36 are patterned after Lacis and Hansen [12], as shown in Eqs. 15 and 16: Some of the terms in the expression for ozone absorption used by Lacis and Hansen have been dropped in Eq. 34. This expression is still much too complicated when the relative importance of ozone is considered. The second line of Eq. 34 could be dropped without serious effects. The form of Eq. 33 can be simplified by removing the $\left(1.0+M^{\prime}-\left(M^{\prime}\right)^{1.01}\right)$ term. This simplification provides very accurate results for $z \leqslant 70^{\circ}$.

The second and simplest model is given by

$$
\begin{gathered}
I_{D N}=T_{0}(0.9662)\left[T_{M} \cdots a_{w}\right] T_{A} \\
T_{M}=1.041-0.15\left[M\left(9.368 \times 10^{-4} P+0.051\right)\right]^{0.5}
\end{gathered}
$$

The expressions for $a_{w}$ and $T_{A}$ are the same as Eqs. 36 and 37 , respectively. Equation 40 was used by Atwater and Ball [6], and Eq. 41 is a slight variation of Kastrov as presented by Kondratyev [9]. The variable $P$ is the surface pressure at the location being considered. This model will be shown to provide results that are nearly as accurate as the more complex model with much less effort.

\subsection{ADDITIONAL MODELS AND OTHER CONSIDERATIONS}

This study is not a comprehensive comparison of simple direct insolation models.' It is a comparison of the more recent models. An excellent comparison of other models is presented by Davies and Hay [22].

For the comparison of different models it is useful to know the origin of the data used to formulate the models. An attempt will be made to trace the origins of the $\mathrm{H}_{2} \mathrm{O}, \mathrm{O}_{3}$, and uniformly mixed gas data used in the models described here. In addition, a discussion of air mass and the various forms of the transport equation for direct insolation will be presented.

\subsection{0 .1 Water Vapor}

I'he LOWTRAN model is based on a band absorption model. The parameters in the band absorption model are based on comparisons with transmittance data taken by Burch et al. [23-33] and line-by-line transmittance calculations degraded in resolution to $20 \mathrm{~cm}^{-1}$. The contributors to the line data are too extensive to reference here, but are found in a report by McClatchey et a1. [34].

Atwater and Ball used an empirical expression from McDonald [10] based on old data taken by Fowle [35]. Fowle's data did not account for the weak absorption bands near 0.7- and 0.8- $\mu \mathrm{m}$ wavelengths. Because of the poor documentation of Fowle's data, McDonald could not claim an absolute accuracy greater than $30 \%$. 
The ASHRAE model is based on work by Threlkeld. Hulstrom explicates "Threlkeld determined the variable amount of water vapor on a monthly basis by a semiempirical technique. He used measurements of the broadband direct beam insolation [at Blue Hull, Mass.; Lincoln, Neb.; and Madison, Wis.] in conjunction with the Moon calculation routine, to derive indirectly the corresponding amount of precipitable water vapor" [17].

Hoyt and also Lacis and Hansen used water vapor from Yamamoto [36]. Lacis and Hansen explain, "Absorption by major water vapor bands has been measured at low spectral resolution by Howard et al. (1956). Yamamoto (1962) weighted these absorptivities with the solar flux and summed them, including estimates for the weak absorption bands near 0.7 and $0.8 \mu \mathrm{m}$ which were not measured by Howard et al., to obtain the total absorption as a function of water vapor amount" [12]. The reference to Howard et a1. is referenced here as [37].

Watt used an expression for water vapor that he derived empirically from data in Chapter 16 of Valley [38]. He then compared this expression with measured data from several locations and adjusted the coefficients to obtain the best agreement.

Machta based his model on calculations performed by Braslau and Dave [14] with a rigorous radiative transfer code. Braslau and Dave hased their calculations on the database used by LOWTRAN. However, they used a mathematical formalism different from LOWTRAN for band absorption.

\subsection{0 .2 Ozone}

The LOWTRAN and Machta models used the same original data sources for all the molecular absorbers. The references given in the previous section for water vapor are the same for ozone.

Atwater and Ball did not consider ozone separately but used a general formula that included all molecular effects except water vapor absorption.

The ASHRAE and Watt. models are based on the ozone data used by Moon [19]. Moon, in turn, used data measured by Wulf [39] in the Chappuis band (0.5 to $0.7 \mu \mathrm{m})$. and data by Lauchli [40] in the Hartley-Huggins band below $0.35 \mu \mathrm{m}$ wavelength.

Watt integrated the spcctral data given by Moon to obtain broadband ozone absorption. He then modified an expression that agreed with these results to give the best agreement with broadband total transmittance data from other sources.

Hoyt used ozone data from Manabe and Strickler [41] to derive an empirical formula. Manabe and strickler based their results on experimental data from Vigroux [42] and Inn and Tanaka [43]. Lacis and Hansen apparently, based their empirical formula for ozone on the same original data sources that Hoyt used. They point out that the data for wavelengths greater than $0.34 \mu \mathrm{m}$ were given for $18^{\circ} \mathrm{C}$. They used the data at $-44^{\circ} \mathrm{C}$ for shorter wavelengths and reduced the longer wavelength data by $25 \%$ to compensate for the ditference in temperature. They produced separate expressions appropriate. for the ultraviolet and visible absorption data, respectively. 


\subsubsection{Uniformly Mixed Gases}

The uniformly mixed gases are $\mathrm{CO}_{2}$ and $\mathrm{O}_{2}$. LOWTRAN and Machta are based on the same original data sources given in the section about water vapor.

The ASHRAE and Watt models are based on Moon's model. Moon did not consider $\mathrm{CO}_{2}$ and $\mathrm{O}_{3}$ in insolation but might have included their effect with $\mathrm{H}_{2} \mathrm{O}$ absorption.

Atwater and Ball based their model on an empirical formula that included all molecular effects except water vapor absorption according to Kondratyev [9]. This formula was based originally on Fowle's data for the constant gases.

Hoyt used Yamanoto's oxygen absorption data, which in turn were laken from Howard et al. [44]. The carbon dioxide data were taken from Burch et a1. [45].

A summary of the data sources used by various modelers is condensed in Table 2-1.

Table 2-1. SOURCES OF DATA FOR. CONSTRUCTION OF MODELS

\begin{tabular}{|c|c|c|c|}
\hline Mode1 & $\mathrm{H}_{2} \mathrm{O}$ & $o_{3}$ & $\mathrm{CO}_{2}+\mathrm{O}_{2}$ \\
\hline SOLTRAN & $\begin{array}{l}\text { Burch et al. (many) } \\
\text { Line-by-line data }\end{array}$ & $\begin{array}{l}\text { Burch et al. (many) } \\
\text { LIne-by-line data }\end{array}$ & $\begin{array}{l}\text { Burch et al. (many) } \\
\text { Line-by-line data }\end{array}$ \\
\hline Atvator and $B a 11$ & $\begin{array}{l}\text { Fowle } \\
\text { (McDonald) }\end{array}$ & Kaslrov & $\begin{array}{l}\text { fowle } \\
\text { (Kastrov) }\end{array}$ \\
\hline Hoyt & $\begin{array}{l}\text { Howard et al. (1955) } \\
\text { (Yamamoto) }\end{array}$ & $\begin{array}{l}\text { Vigroux } \\
\text { Inn and Tanaka } \\
\text { (Wanabe \& Strickler) }\end{array}$ & $\begin{array}{l}\text { Burch et al. (1960) } \\
\text { Howard et al. (1955) }\end{array}$ \\
\hline Watt & Valley \& Modifications & $\begin{array}{l}\text { Wulf } \\
\text { Lauch11 } \\
\text { (Moon) }\end{array}$ & Moon \\
\hline Lacis and Hansen & $\begin{array}{l}\text { Howard et al. (1955) } \\
\text { (Yamamoto) }\end{array}$ & $\begin{array}{l}\text { V1groux } \\
\text { Inn and Tanaka } \\
\text { (Howard et al. } 1961 \text { Handbook). }\end{array}$ & \\
\hline ASHRAE & $\begin{array}{l}\text { Threlkeld } \\
\text { (Best fit } 3 \text { locations) }\end{array}$ & $\begin{array}{l}\text { Wulf } \\
\text { Lauchli } \\
\text { (Moon) }\end{array}$ & Monn \\
\hline Machea & $\begin{array}{l}\text { Burch et al. (many) } \\
\text { Line-by-1ine data } \\
\text { (Dave) }\end{array}$ & $\begin{array}{l}\text { Burch ot al. (many) } \\
\text { Line-by-line data } \\
\text { (Dave) }\end{array}$ & $\begin{array}{l}\text { Bureh et al. (many) } \\
\text { Line-by-11ne data } \\
\text { (Dave) }\end{array}$ \\
\hline
\end{tabular}




\subsection{0 .4 Air Mass}

The air mass is a coefficient that accounts for the increased path length through which light rays must pass in the atmosphere when the sun is not directly overhead. When the sun is directly overhead, the air mass is 1.0 . The formal definition of air mass is given by Kondratyev [9] as

$$
M=\int_{0}^{\infty} \rho \mathrm{d} s / \int_{0}^{\infty} \rho \mathrm{d} z,
$$

where $\mathrm{d} z$ is an increment in the vertical direction; $d s$ is an increment along a slanted path; and $\rho$ the density of air, or whatever component of the air that is being considered. This definition implies that differences in altitude between different surface locations must be accounted for by some means other than air mass. In calculating atmospheric attenuation over a slant path, for example, the optical depth for a vertical path is multiplied by the air mass to obtain the total optical depth. The vertical optical depth includes the effect of the altitude at which one is working. Some authors include the beginning altitude in the air mass and use the optical depth from sea level, or $1013 \mathrm{mb}$ pressure. This is called the absolute, or pressure-corrected, air mass, given by

$$
M^{\prime}=\frac{P}{P_{0}} M,
$$

where $\mathrm{P}_{0}=1013 \mathrm{mb}$.

Kondratyev [9] summarizes the methods of calculation for different ranges of zenith angle. For zenith angles $<60^{\circ}$, sufficient accuracy can be ubtained using

$$
M=\sec 2,
$$

where $\mathrm{Z}$ is the zenith angle. For $60^{\circ} \leqslant z \leqslant 80^{\circ}$, the effect of earth curvature becomes important. Geometric considerations give

$$
M=\left\{(r / H)^{2} \cos ^{2} Z+2(r / H)+1\right\}^{1 / 2}-(r / H) \cos Z,
$$

where $r$ is the earth's radius and $H$ the scale height defined by

$$
H=\int_{0}^{\infty} \frac{\rho}{\rho_{0}} d z .
$$


The constant $\rho_{0}$ is the surface level density. For air or the uniformly mixed gases, $\mathrm{H}=\mathrm{P}_{0} /\left(\rho_{0} g\right)$, where $\mathrm{g}$ is the acceleration due to gravity and $\mathrm{P}_{0}$ is the surface level pressure.

For $z>80^{\circ}$, the effects of refractive index become important. The correct value of air mass in this region can be found in tables (Kondratyev, for example) or can be calculated with approximate expressions. An expression that this author has found to be correct to within $1 \%$ for $Z<89^{\circ}$ is defined by Kasten [21] to be

$$
M=\left\{\cos z+0.15(93.885-z)^{-1.253}\right\}^{-1}
$$

This expression was used in the results given in this report (11n less otherwice noted), and is called the relative air mass by Kasten.

\subsubsection{S1mple Transport Equation}

Several forms of the transport equation have been used in the models described here. Some possible forms of the equation are:

$$
\begin{gathered}
I_{1}=I_{0} T_{R} T_{0} T_{u} T_{w} T_{A}, \\
I_{2}=I_{0}\left[T_{R} T_{0} T_{u}-a_{w}\right] T_{A}, \\
I_{3}=I_{0}\left[T_{R} T_{0}-a_{w}-a_{u}\right] T_{A}, \\
I_{4}=I_{0}\left[T_{M}-a_{w}\right] \mathrm{I}_{A},
\end{gathered}
$$

where $T_{R}$ is the transmittance due to Rayleigh scattering, $T_{0}$ is the transmittance of ozone, $\mathrm{T}_{\mathrm{u}}$ is the transmittance of the uniformly mixed gases $\mathrm{CO}_{2}$ and $\mathrm{O}_{2}, \mathrm{~T}_{\mathrm{w}}$ and $\mathrm{a}_{\mathrm{w}}$ are the transmittance and absorptance of watcr vapor, $\mathrm{T}_{\mathrm{A}}$ is the transmittance of the aerosol, and $T_{M}$ is the transmittance of all molecular cffects excepl water vápor absorption.

Tables 2-2 and 2-3 were constructed using all forms of the transport equation (Eqs. 48-51) with Bird Models and the results from SOLTRAN. Two standard atmospheres that are built into SOLTRAN were used: the midlatitude summer (MLS) and Llie subarctic winter (SAW) models with sea level visibilities of 23 and $5 \mathrm{~km}$.

Based on the results in Tables $2-2$ and $2-3$, it appears that Eq. 48 provides the closest agreement with SOLTRAN. The very simple form of Eq. 50 provides results that are comparable to Eq. 48. A theoretical basis for selecting any one of these forms of the transport equation as the best has not been established by the authors. However, one assumption implicit in Eq. 48 is that the attenuation by each constituent is independent of every other constituent. In other words, the transmittance measured in pure materials can be combined in the form of $\mathrm{Eq}$. 48 to produce the transmittance through a mixture of 
Table 2-2. COMPARISONS OF DIRECT NORMAL IRRADIANCE FOR DIFFERENT FORMS OF THE TRANSPORT EQUATION USING BIRD MODELS AND SOLTRAN

\begin{tabular}{|c|c|c|c|c|c|c|}
\hline $\begin{array}{l}\text { Zenith } \\
\text { Angle } \\
\text { (deg) }\end{array}$ & $\begin{array}{c}\text { Mode1 } \\
\text { Atmosphere }\end{array}$ & $\begin{array}{c}\mathrm{I}_{1} \\
\left(\mathrm{~W} / \mathrm{m}^{2}\right)\end{array}$ & $\begin{array}{c}\mathrm{I}_{2} \\
\left(\mathrm{~W} / \mathrm{m}^{2}\right)\end{array}$ & $\begin{array}{c}\mathrm{I}_{3} \\
\left(\mathrm{~W} / \mathrm{m}^{2}\right)\end{array}$ & $\begin{array}{c}I_{4} \\
\left(W / m^{2}\right)\end{array}$ & $\begin{array}{r}\text { SOLTRAN } \\
\left(\mathrm{W} / \mathrm{m}^{2}\right)\end{array}$ \\
\hline 0.0 & MLS & 827.1 & 812.5 & 811.2 & 816.6 & 833.5 \\
\hline 20.0 & $\mathrm{~V}=23 \mathrm{~km}$ & 811.0 & 795.7 & 794.2 & 800.1 & -- \\
\hline 30.0 & 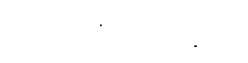 & 789.0 & 772.8 & 771.3 & 777.8 & -- \\
\hline 40.0 & & 754.5 & 736.9 & 735.2 & 742.8 & 756.6 \\
\hline 50.0 & & 702.1 & 682.3 & 680.4 & 690.0 & - \\
\hline 60.0 & & 621.3 & 598.5 & 596.2 & 609.1 & 617.7 \\
\hline 70.0 & & 490.2 & 463.3 & 460.6 & 478.4 & -- \\
\hline 75.0 & & 392.3 & 363.5 & 360.5 & 380.5 & 386.3 \\
\hline 80.0 & & 261.7 & 233.0 & 229.9 & 248.7 & 258.9 \\
\hline 85.0 & & 101.5 & 81.8 & 79.5 & 84.3 & 102.8 \\
\hline 0.0 & MLS & 545.8 & 536.2 & 535.3 & 538.9 & 530.6 \\
\hline 20.0 & $\mathrm{~V}=5 \mathrm{~km}$ & 522.4 & 512.6 & 511.7 & 515.4 & -- \\
\hline 30.0 & & 491.4 & 481.3 & 480.3 & 484.4 & -- \\
\hline 40.0 & & 444.4 & 434.0 & 433.0 & 437.5 & -- \\
\hline 50.0 & & 377.4 & 366.8 & 365.8 & 370.9 & $-=$ \\
\hline 60.0 & & 285.1 & 274.6 & 273.5 & 279.5 & 270.3 \\
\hline 70.0 & . & 163.8 & 154.8 & 153.8 & 159.8 &.- \\
\hline 75.0 & & 96.2 & 89.2 & 88.4 & 93.4 & -97.2 \\
\hline 80.0 & & 35.8 & 31.9 & 31.4 & 34.0 & 42.4 \\
\hline 85.0 & & 3.1 & 2.5 & 2.4 & 2.6 & 7.0 \\
\hline
\end{tabular}


Table 2-3. COMPARISONS OF DIRECT NORMAL IRRADIANCE FOR DIFFERENT FORMS OF THE TRANSPORT EQUATION USING BIRD MODELS AND SOLTRAN

\begin{tabular}{|c|c|c|c|c|c|c|}
\hline $\begin{array}{l}\text { Zenith } \\
\text { Angle } \\
\text { (deg) }\end{array}$ & $\begin{array}{c}\text { Model } \\
\text { Atmosphere }\end{array}$ & $\begin{array}{c}\mathrm{I}_{1} \\
\left(\mathrm{~W} / \mathrm{m}^{2}\right)\end{array}$ & $\begin{array}{c}\mathrm{I}_{2} \\
\left(\mathrm{~W} / \mathrm{m}^{2}\right)\end{array}$ & $\begin{array}{c}\mathrm{I}_{3} \\
\left(\mathrm{~W} / \mathrm{m}^{2}\right)\end{array}$ & $\begin{array}{c}I_{4} \\
\left(\mathrm{~W} / \mathrm{m}^{2}\right)\end{array}$ & $\begin{array}{r}\text { SOLTRAN } \\
\left(w / m^{2}\right)\end{array}$ \\
\hline 0.0 & SAW & 866.0 & 856.5 & 855.1 & 865.5 & 881.9 \\
\hline 20.0 & $\mathrm{~V}=23 \mathrm{~km}$ & 849.4 & 839.5 & 838.0 & 848.9 & -- \\
\hline $3 \cap .0$ & & 826.8 & 016.3 & 814.7 & 826.4 & -- \\
\hline 40.0 & & 791.2 & 779.7 & 778.0 & 791.1 & 804.3 \\
\hline 50.0 & & 737.2 & 724.0 & 722.0 & 737.5 & -- \\
\hline 60.0 & & 653.0 & 637.9 & 635.6 & 654.7 & 662.5 \\
\hline 70.0 & & 515.9 & 498.0 & 495.1 & 519.6 & -- \\
\hline 75.0 & & 413.0 & 393.7 & 390.5 & 417.2 & 423.3 \\
\hline 80.0 & & 275.3 & 255.9 & 252.6 & 277.3 & 289.0 \\
\hline 85.0 & & 106.2 & 92.6 & 90.2 & 98.8 & 120.0 \\
\hline 0.0 & SAW & 571.5 & 565.2 & 564.3 & 571.2 & 568.5 \\
\hline 20.0 & $\mathrm{~V}=5 \mathrm{~km}$ & 547.2 & 510.8 & 539.8 & 546.9 & -- \\
\hline 30.0 & & 514.9 & 508.3 & 507.4 & 514.7 & -- \\
\hline 40.0 & & 466.0 & 459.2 & 458.2 & 465.9 & 461.1 \\
\hline 50.0 & & 396.2 & 389.2 & 388.1 & 396.4 & -- \\
\hline 60.0 & . & 299.6 & 292.7 & 291.6 & 300.4 & 297.8 \\
\hline 70.0 & & 172.3 & 166.3 & 165.4 & 173.6 & - \\
\hline 75.0 & & 101.3 & 96.6 & 95.8 & 102.3 & 112.0 \\
\hline 80.0 & & 37.6 & 35.0 & 34.5 & 37.9 & 50.5 \\
\hline 85.0 & & 3.3 & 2.8 & 2.8 & 3.0 & 9.0 \\
\hline
\end{tabular}


materials. One obvious situation that violates this assumption is when nearcomplete absorption in a single constituent occurs within the spectral band being considered. If one of the other constituents absorbs in the same spectral location, over attenuation will occur in the final results. The form of Eqs. 49 and 50 make this situation even worse. 


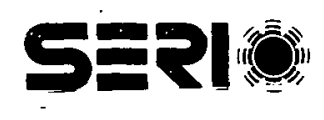

c 
SECTION 3.0

MODEL COMPARISONS

Where possible, each of the models was programmed on a computer to produce data for comparison. Parts of the Hoyt model were generated with a programmable hand calculator, and data from the Machta model were, generated by using the worksheet format presented with the model.

General transmittance data for the midlatitude summer (MLS) and the subarctic winter (SAW) atmospheric models have been generated with the SOLTRAN code. These atmospheric models are two of the standard atmospheres defined in SOLTRAN. They were chosen primarily because the amounts of ozone and water vapor defined in them represent extremes that could be encountered in the United States. The Rayleigh scattering due to molecules and the absorption of the uniformly mixed gases $\left(\mathrm{CO}_{2}\right.$ and $\left.\mathrm{O}_{2}\right)$ are relatively constant in these models. The aerosol conditions can be defined independently of the atmospheric model. As was mentioned previously, the results from the SOLTRAN code are for a spectral interval between 0.3 to $3.0 \mathrm{~mm}$. If the calculations would have been made from 0.25 to $10.0 \mathrm{~m}$, the results from SOLTRAN for individual atmospheric constituents could change. However, the total transmittance of al1 constituents should not change appreciably $(<1 \%)$.

The amounts of ozone and water vapor in the SAW model are $0.45 \mathrm{~cm}$ of ozone and $0.42 \mathrm{~cm}$ of water vapor. The amounts in the MLS model are $0.31 \mathrm{~cm}$ of ozone and $2.93 \mathrm{~cm}$ of water vapor. Figure $3-1$ presents a plot of the broadband $(0.3$ to $3.0 \mathrm{um}$ ) transmittance versus sec $Z$ for all of the atmospheric components in the MLS model. Figure 3-2 presents the same type of results for the SAW model atmosphere. Both figures contain the results for a 23-km visibility aerosol at sea level. The aerosol used in this paper is the one defined in the LOWTRAN 3 version, and is representative of a continental or rural aerosol.

Figures 3-1 and 3-2 show the relative importance of each atmospheric component as an attenuater of troadband radiation $(0.3-3.0 \mathrm{jm}) . \mathrm{CO}_{2}$ and $\mathrm{O}_{2}$ are the least important elements, and they are omitted from some models. The next element exhibiting increased attenuation is $\mathrm{O}_{3}$, followed by $\mathrm{H}_{2} \mathrm{O}$. The flattening of the curve for $\mathrm{H}_{2} \mathrm{O}$ in Fig. 3-1 with increasing zenith angle suggests that the $\mathrm{H}_{2} \mathrm{O}$ absorption bands are approaching saturation. Molecular scattering (Rayleigh scattering) dominates total molecular absorption at large zenith angles and has a greater effect than most individual molecular species at all zenith angles. The one exception to this statement appears to be $\mathrm{H}_{2} \mathrm{O}$ absorption for high concentrations of $\mathrm{H}_{2} \mathrm{O}$ and for air masses < 2. The most significant-attenuacor at nearly all zenith angles is the aerosnl.

An aerosol that produces a 23-km meteorological range at sea level is considered to produce a relatively clear atmosphere. At higher surface altitudes and remote locations, it is not uncommon during winter months to observe meteorological ranges greater than $60 \mathrm{~km}$, which are extremely clear condiLiuns. The data precented in Figs. 3-1. and 3-2 suggest that aerosol attenuation could be the most important attenuator at most locations throughout the United States. Unfortunately, it is also the component that is the most 


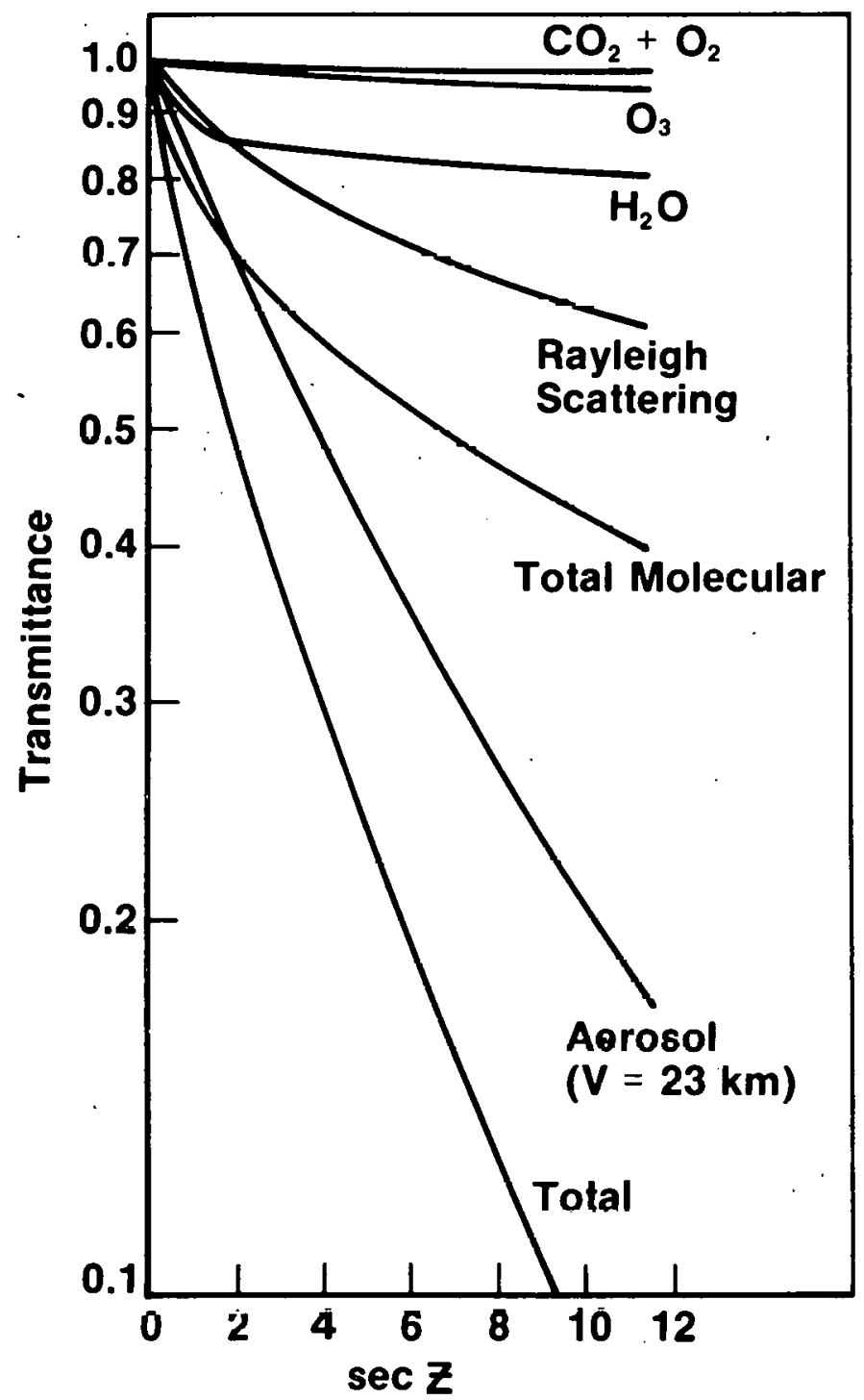

Figure 3-1. Transmittance versus Secant of Solar Zenith Angle for Midlatitude Summer Model 


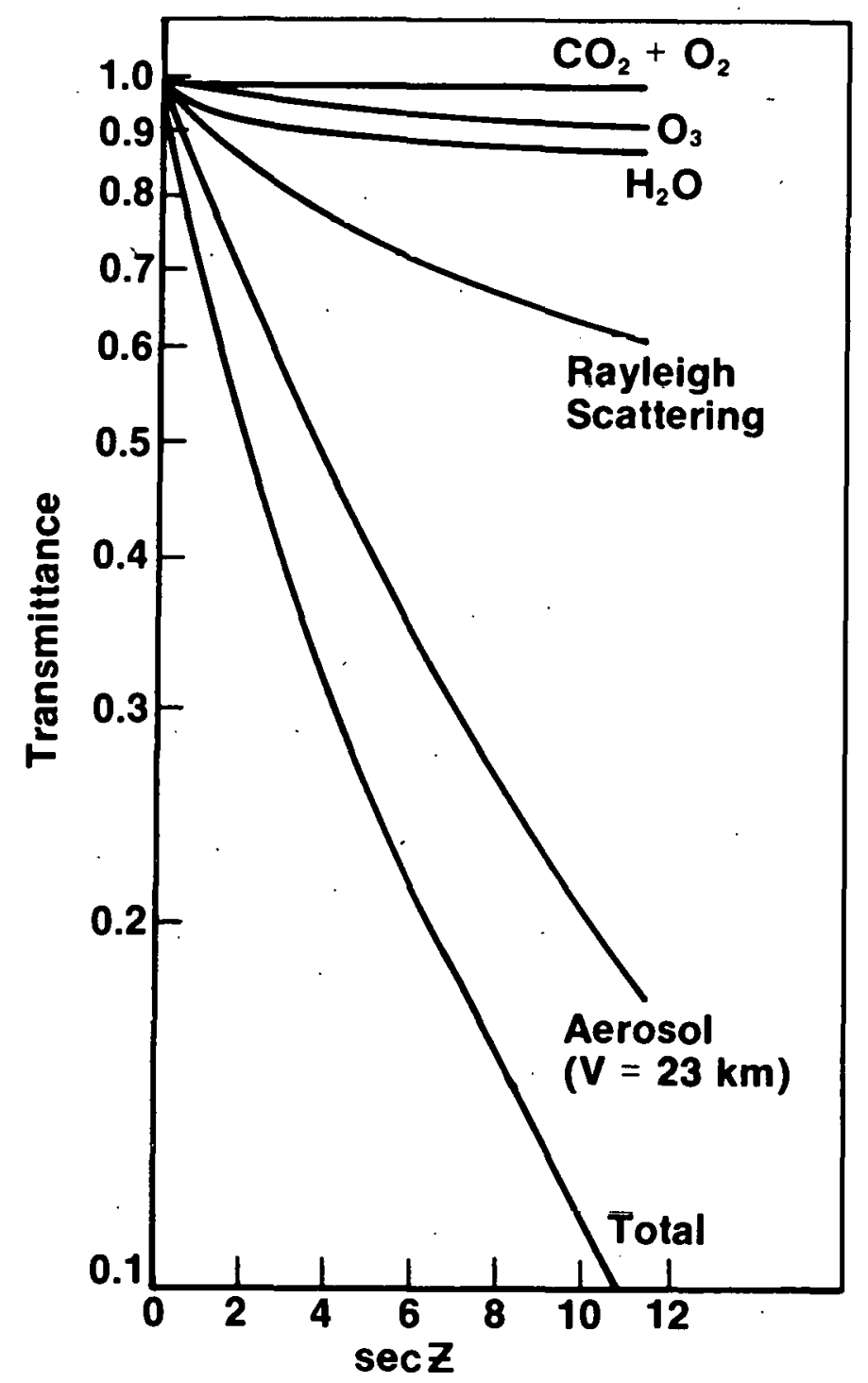

Figure 3-2. Transmittance versus Secant of Solar Zenith Angle for Subarctic Winter Model 
difficult to measure and hence the least defined. It should be emphasized that these conclusions are for broadband (thermal) direct insolation, and that the situation will change significantly as the bandwidth is further restricted or global insolation is considered.

The previous section noted that the ASHRAE model assumes a plot of the total transmittance shown in Figs. 3-1 and 3-2 will scribe a straight line. The slope of this line provides the optical depth. An examination of Figs. 3-1 and 3-2 demonstrates that this assumption is reasonable over a limited range of zenith angles. If the plot were of irradiance versus sec $Z$, the vertical intercept at $\sec Z=0$ would provide the extraterrestrial irradiance, which is usually too low.

Figures 3-3 and 3-4 present $O_{3}$ absorption data for five of the models described earlier. Figure $3-3$ is for $0.31 \mathrm{~cm}$ of $O_{3}$ (MLS), and Fig. 3-4 is for $0.45 \mathrm{~cm}$ of $\mathrm{O}_{3}$ (SAW). The models produce significantly different results when compared in this manner. However, the differences are minor when the effectiveness of $\mathrm{O}_{3}$ is accounted for. The triangular data points are a result of performing a least squares fit to the SOLTRAN data with the equations of Lacis and Hansen (Bird model). The minor deviations of the triangles from the SOLTRAN data are a result of attempting to fit a simple expression to various amounts of $\mathrm{O}_{3}$.

Figures 3-5 and 3-6 present model comparisons of $\mathrm{H}_{2} \mathrm{O}$ absorption for the two standard atmospheres being considered. Since $\mathrm{H}_{2} \mathrm{O}$ absorption plays a significant role in transmission calculations, the differences between the model.s should be noticeable in the total transmission.

Figures 3-7 and 3-8 present plots of transmittance versus solar zenith angle for all molecular effects except $\mathrm{H}_{2} \mathrm{O}$ absorption for the SAW and MLS atmospheric models, respectively. Some of the models did not readily lend themselves Lo this particular calculation and are not included. The surprise. ubuut chese dala is the accuracy of the simple expression in the Atwater model.

Figures 3-9 and 3-10 illustrate a comparison of aerusul transmittance for the MLS and SAW atmospheric models with sea level visibilities of 5 and $23 \mathrm{~km}$, respectively. In most cases, aerosol attenuation is independent of the atmospheric model; but the Watt model for aprosole io depcndent ou lise dinume of $\mathrm{II}_{2} \mathrm{O}$.

Hoyt's model provides strong agreement with SOLTRAN, but i.ts tabular form i.s not as easily used as empirical formulas. The table covers an insufficient range of turbidity coefficients to include a $5-\mathrm{km}$ visibility aerosol. Hoyt's data are for aerosol scattering only, and there is an additional factor for aerosol absorption in the Hoyt model.

The value of the upper layer turbidity $\mathrm{T}_{\mathrm{u}}$ used in Watt's model was taken from historical plots that he produced. The value used, $\mathrm{T}_{u}=0.02$, was an approximate average of the historical data. The rest of the parameter values for this model were taken directly from SOLTRAN. 


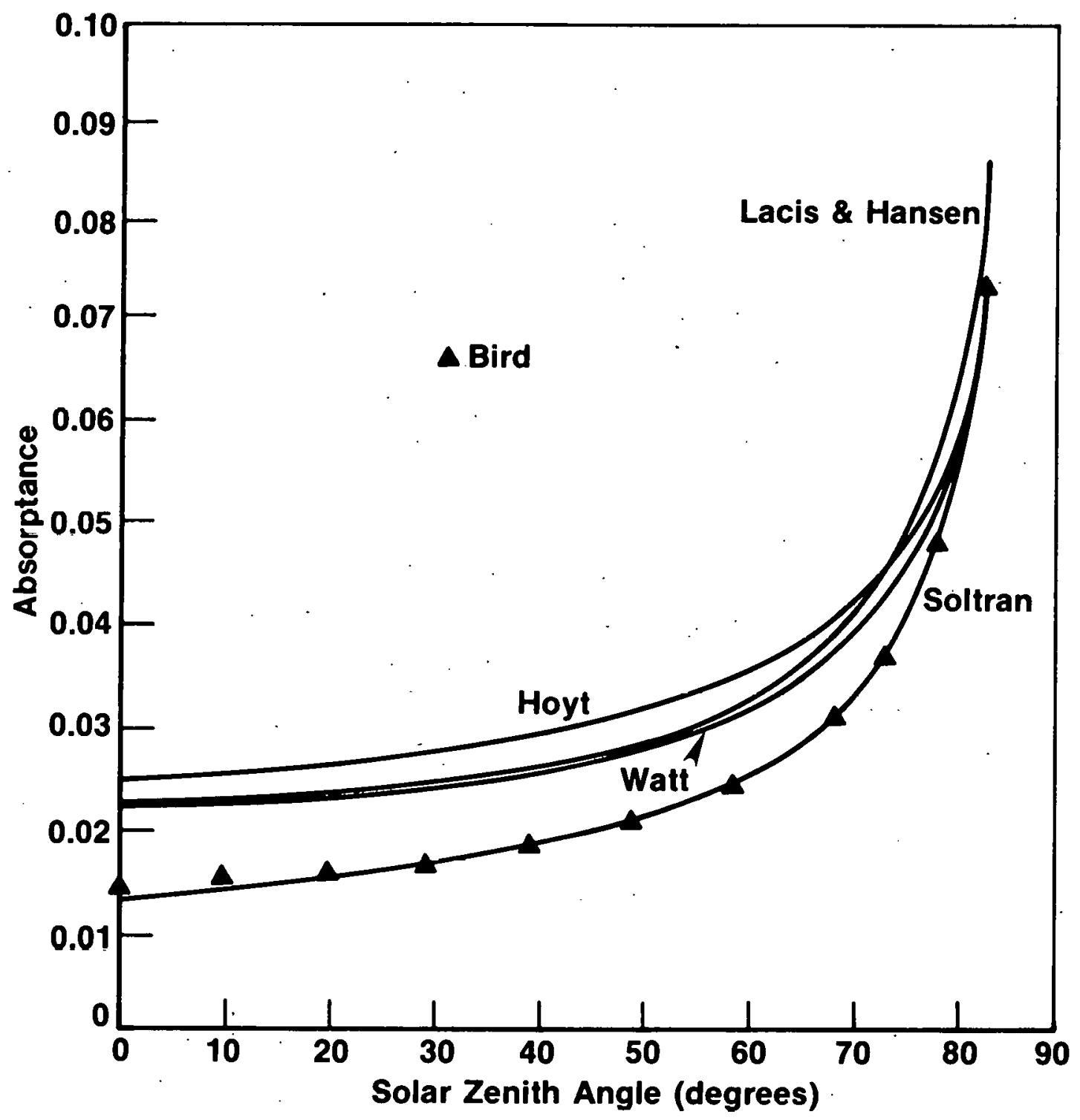

Figure 3-3. Ozone Absorptance versus Solar Zenith Angle for $0.31 \mathrm{~cm}$ of Ozone (MLS) 


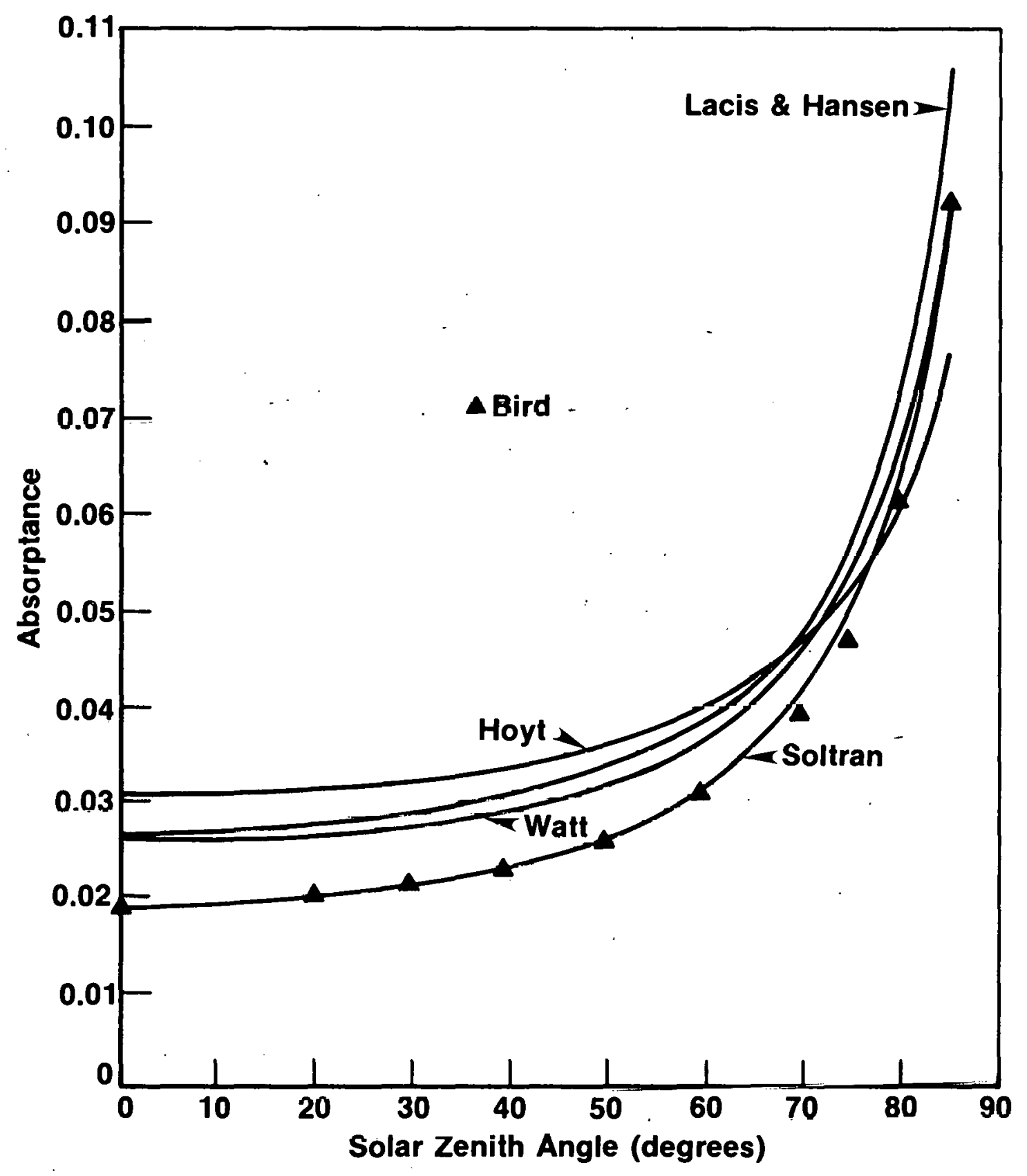

Figure 3-4. Ozone Absorptance versus Solar Zenith Angle for $0.45 \mathrm{~cm}$ of Ozone (SAW) 


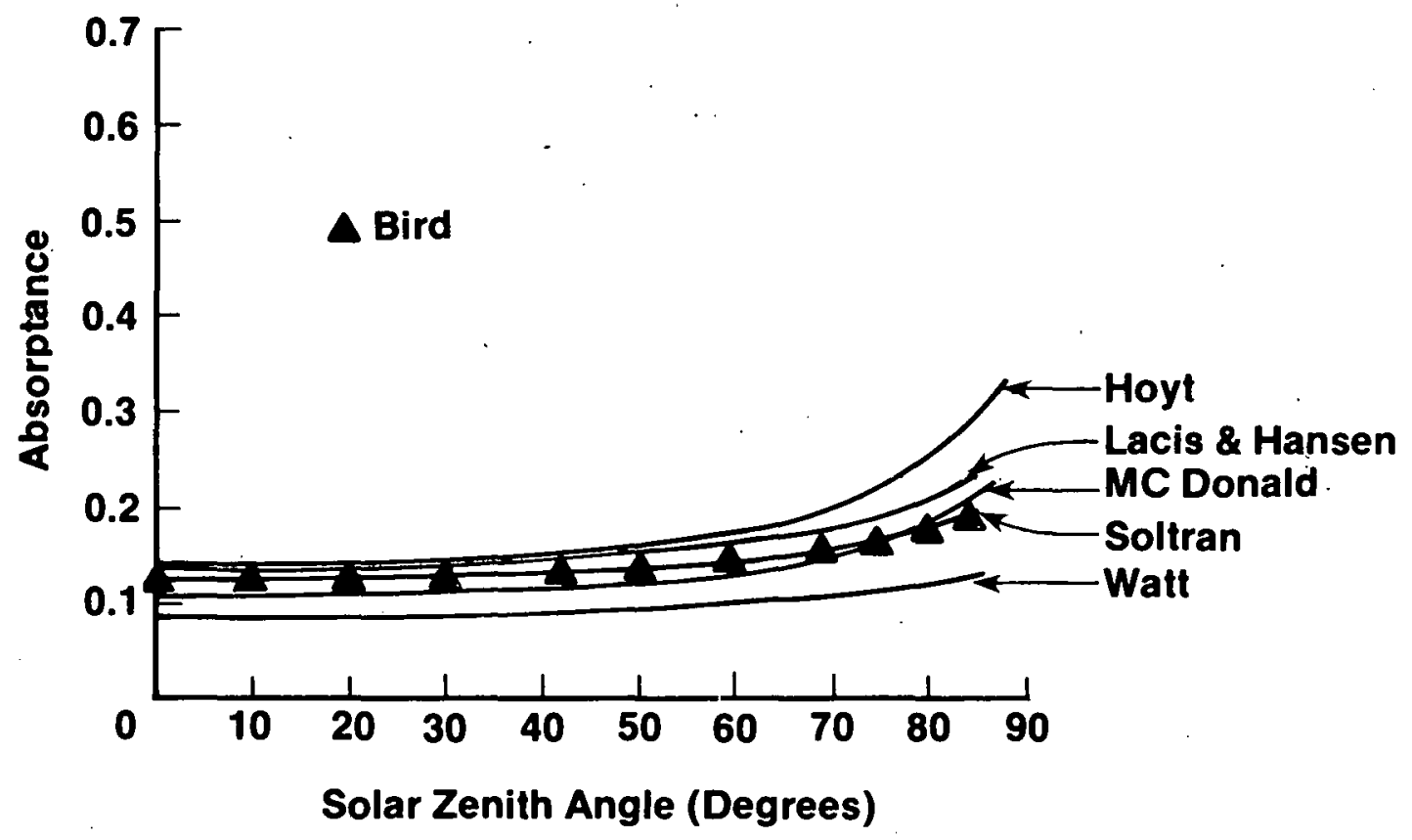

Figure 3-5. Absorptance versus Solar Zenith Angle for $2.93 \mathrm{~cm}$ of Water Vapor (MLS) 


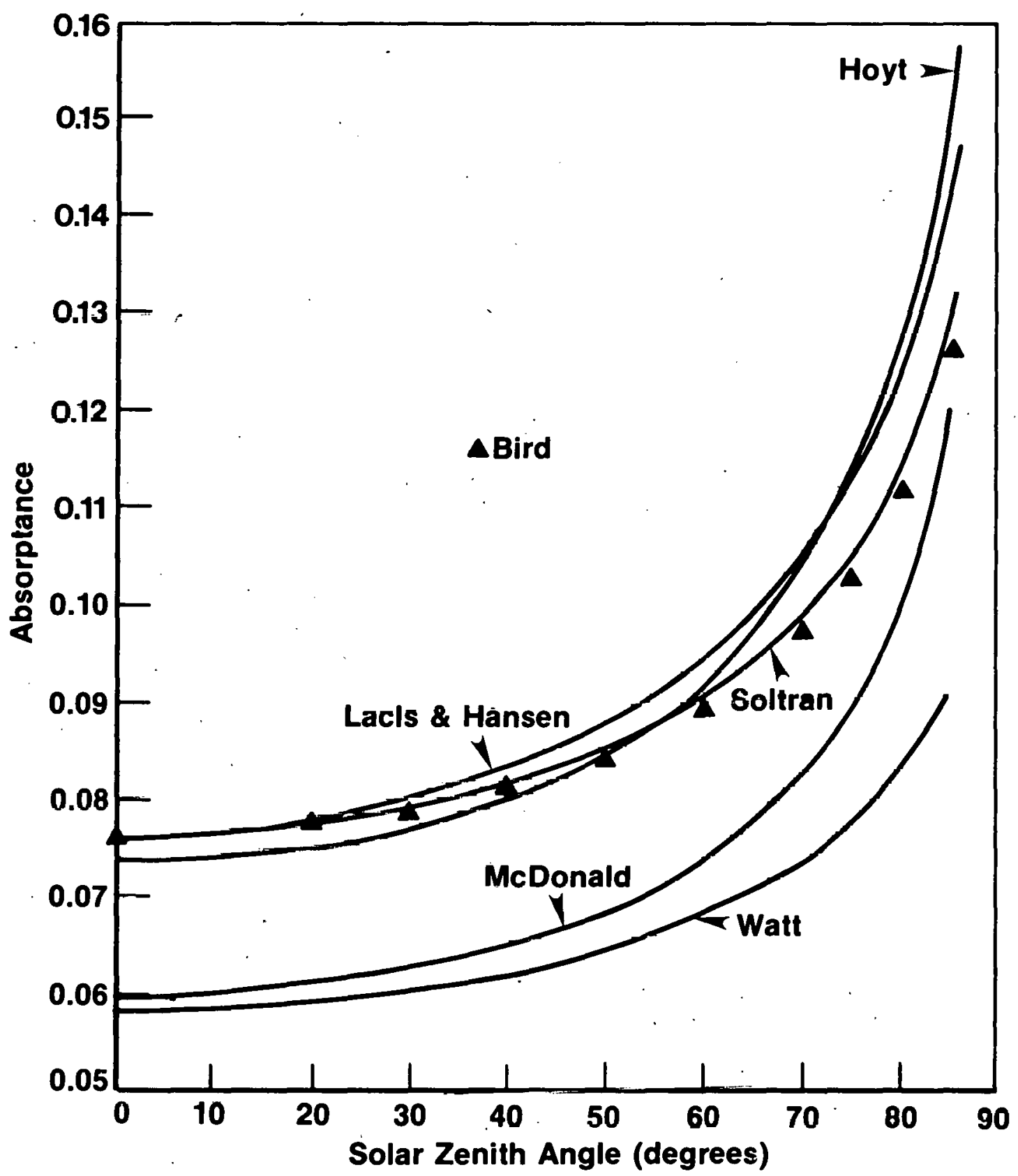

Figure 3-6. Absorptance versus Solar Zenith Angle for $0.42 \mathrm{~cm}$ of Water Vapor (SAW) 


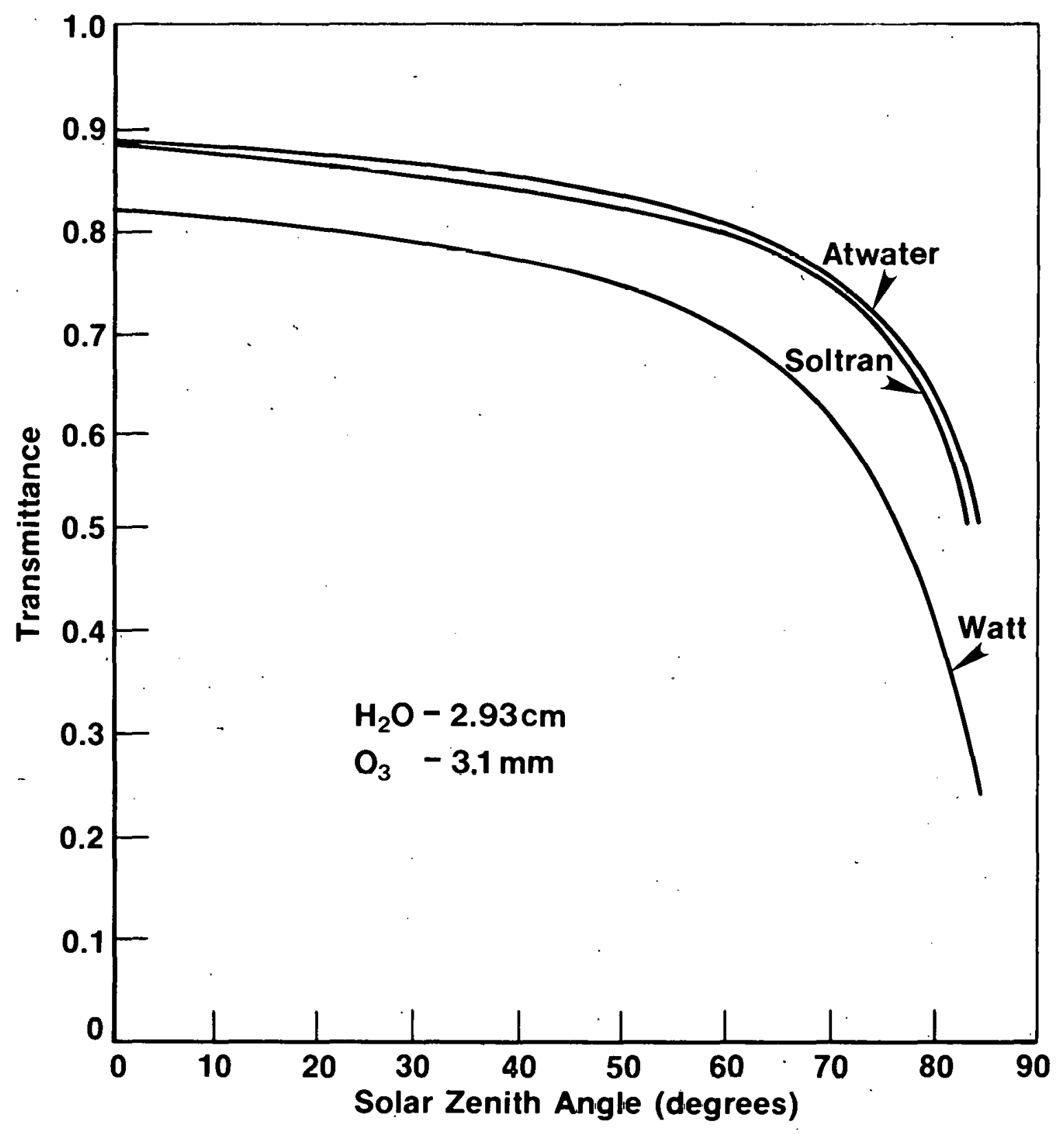

Figure 3-7. Transmittance versus Solar Zenith Angle for All Molecular Effects Except for $\mathrm{H}_{2} \mathrm{O}$ Absorption (MLS) 


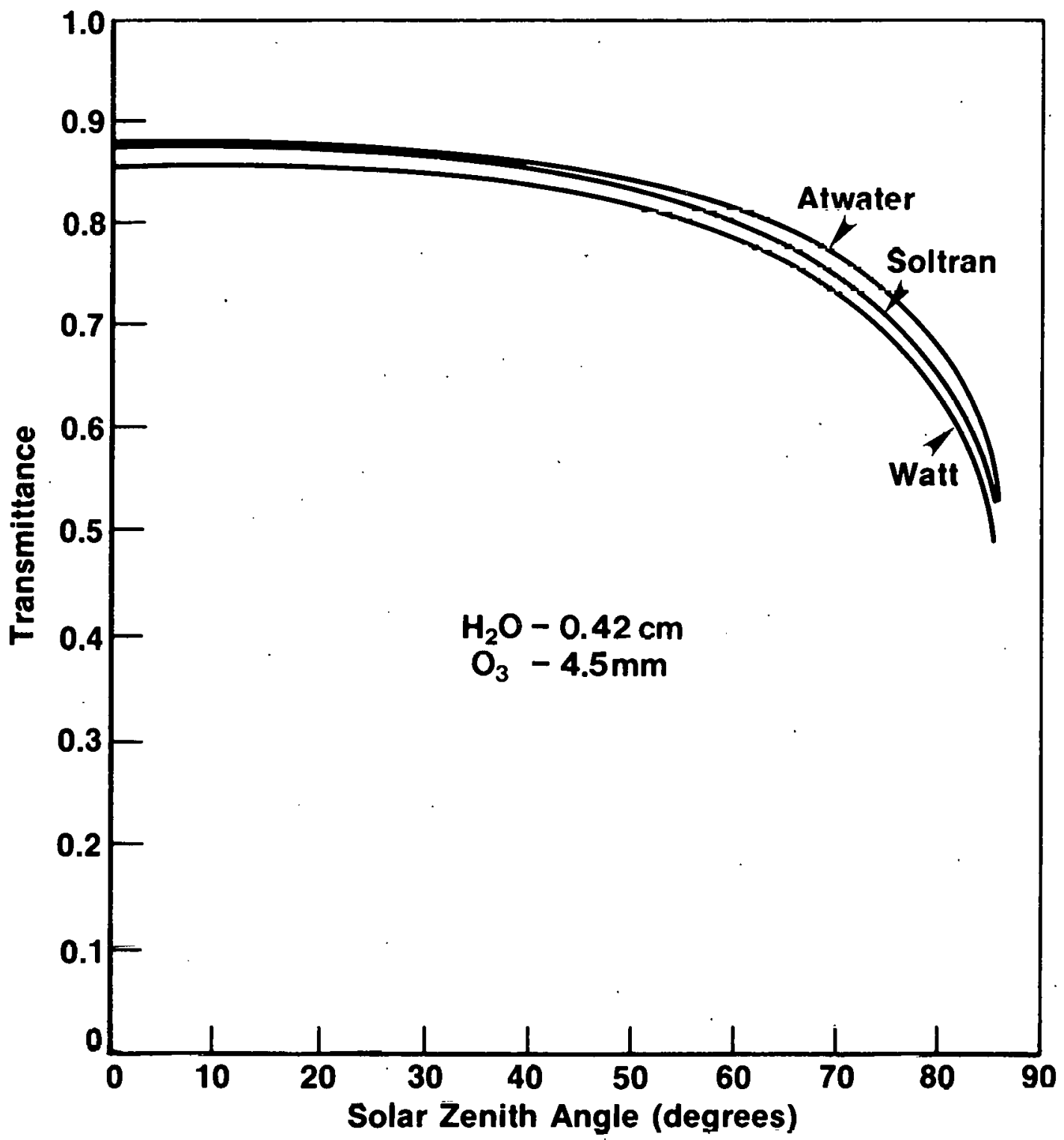

Figure 3-8. Transmittance versus Zenith Angle for All Molecular Effects Except $\mathrm{H}_{2} \mathrm{O}$ Absorption (SAW) 


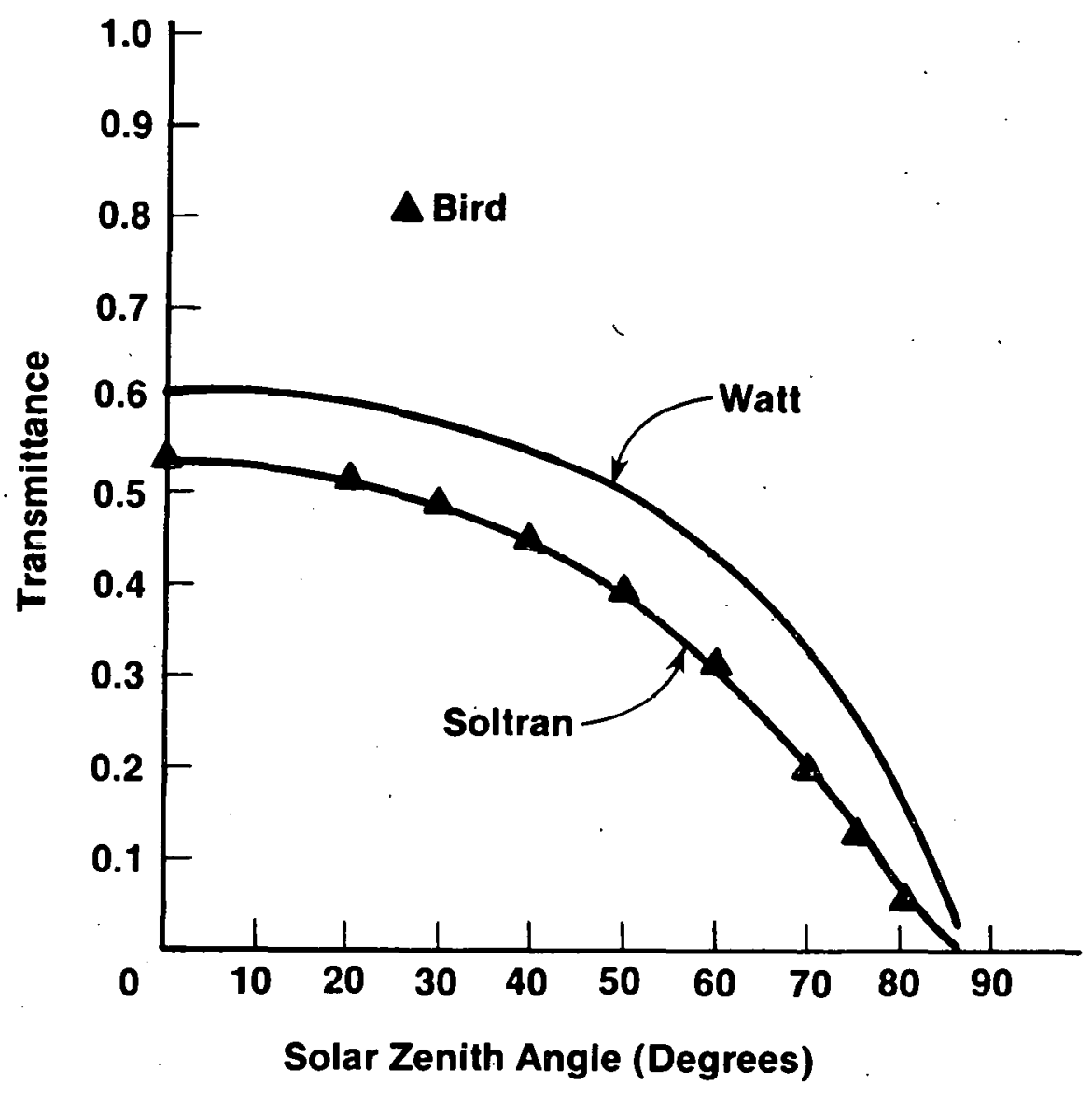

Figure 3-9. Aerosol Transmittance versus Solar Zenith Angle for 5-km Visibility Aerosol 


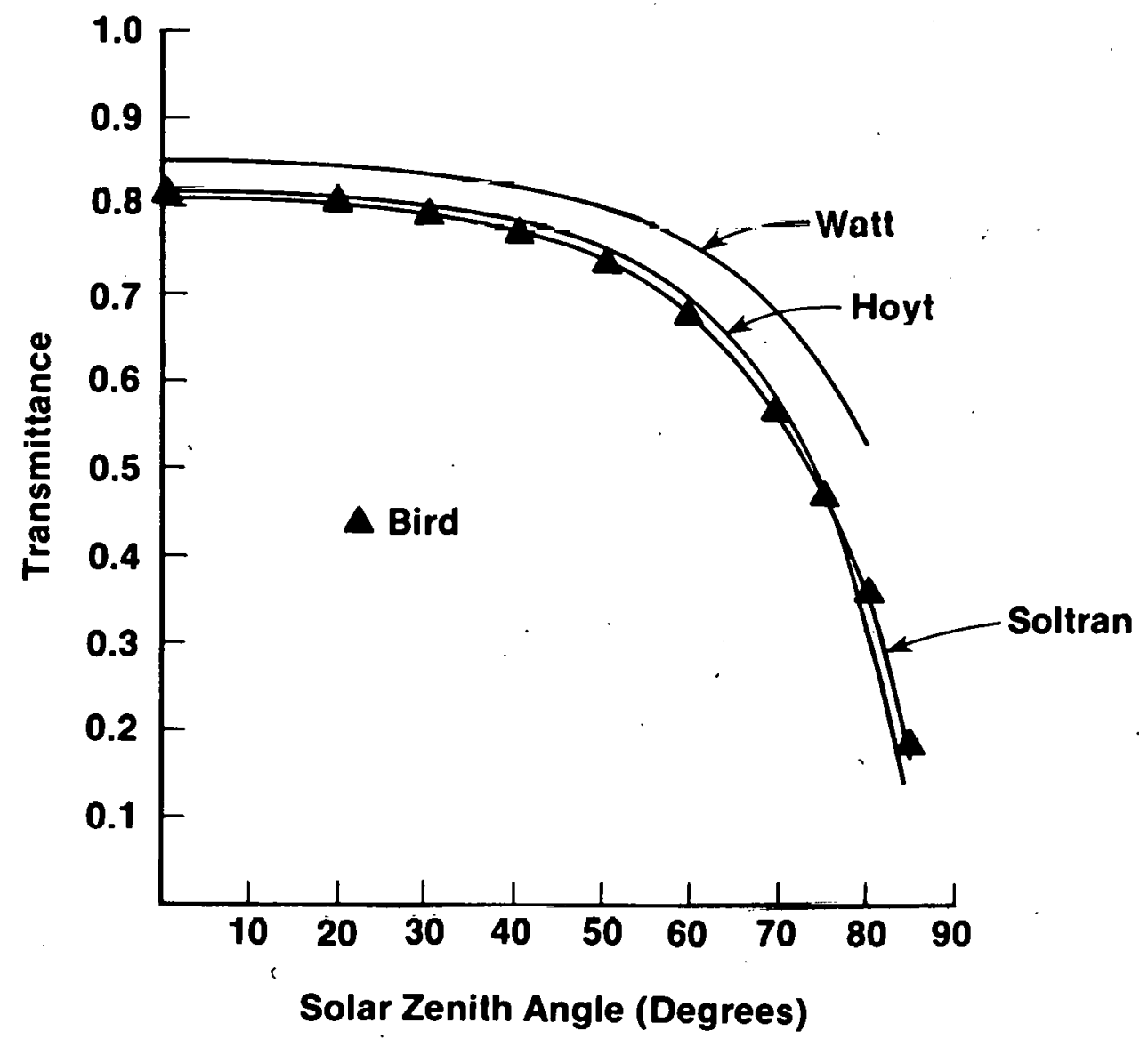

Figure 3-10. Aerosol Transmittance versus Solar Zenith Angle for 23- km Visibility Aerosol 
Figures 3-11 through 3-13 illustrate the total terrestrial solar irradiance as a function of solar zenith angle for several models under different atmospheric conditions. The differences between some of the models are significant. However, the differences illustrated here are dominated by the aerosol attenuation, and the differences due to molecular effects are not obvious. If a much clearer atmosphere were modeled or a more restricted bandwidth were used, the difference in molecular effects would be more evident.

In the results given for the Atwater model, the broadband optical depth for the aerosol was taken from the Bird model. This causes close agreement with the SOLTRAN results, but Figs. $3-7$ and $3-8$ show that the bulk of the molecular attenuation in this model agrees very well with SOLTRAN. Atwater's $\mathrm{H}_{2} \mathrm{O}$ absorption deviates somewhat from SOLTRAN results.

The results for Bird shown in Figs. 3-11, 3-12, and $3-13$ used Eq. 49 as the transport equation.

Because of the difficulty of considering aerosol attenuation and Rayleigh scattering with Hoyt's model, it is included only in Fig. 3-12 and gives values that are lower than the SOLTRAN results over the applicable region.

Machta's model agrees with SOLTRAN within $\pm 5 \%$ to $60^{\circ}$ zenith angle. It is primarily limited to clear air conditions and zenith angles less than $60^{\circ}$. The values shown at $70^{\circ}$ zenith angle are beginning to deviate somewhat.

The Majumdar model results have been given for the MLS atmospheric model with $\mathrm{V}=23 \mathrm{~km}$ ( and has no provision for varying the turbidity. It is evident from Fig. 3-11 that the turbidity resulting from a sea level visibility of $23 \mathrm{~km}$ is too large for this model. The model is very simple, and it could be quite accurate if provisions were made to vary the aerosol attenuation.

Appendix A presents tabular data for each attenuation element for most of the models. Direct normal irradiance for the Bird model is given in Tables 2-2 and 2-3 for the same almuspheric conditions modeled in Appendix A.

This comparison and evaluation of existing simplified models for calculating the direct solar beam energy considered six models - Hoyt, Watt, Lacis and Hansen, Atwater and Ball, Machta, and Majumdar. Ideally, such models should be compared according to the attenuation of each atmospheric constituent. By doing this, differences in calculating the total broadband direct solar energy can be specifically associated with differences in how they calculate attenuation arising from each constituent. However, this was impossible because of the variety of techniques used by the models. For example, some models considered all molecular attenuation processes in a single expression, making it impossible to distinguish. attenuation from specific molecular constituents. The specific comparisons performed considered the following:

- absorptance due to $\mathrm{O}_{3}$ (Lacis and Hansen; Hoyt; Watt),

- absorptance due to water vapor (Lacis and Hansen; Hoyt; Watt; Mc Donald), 


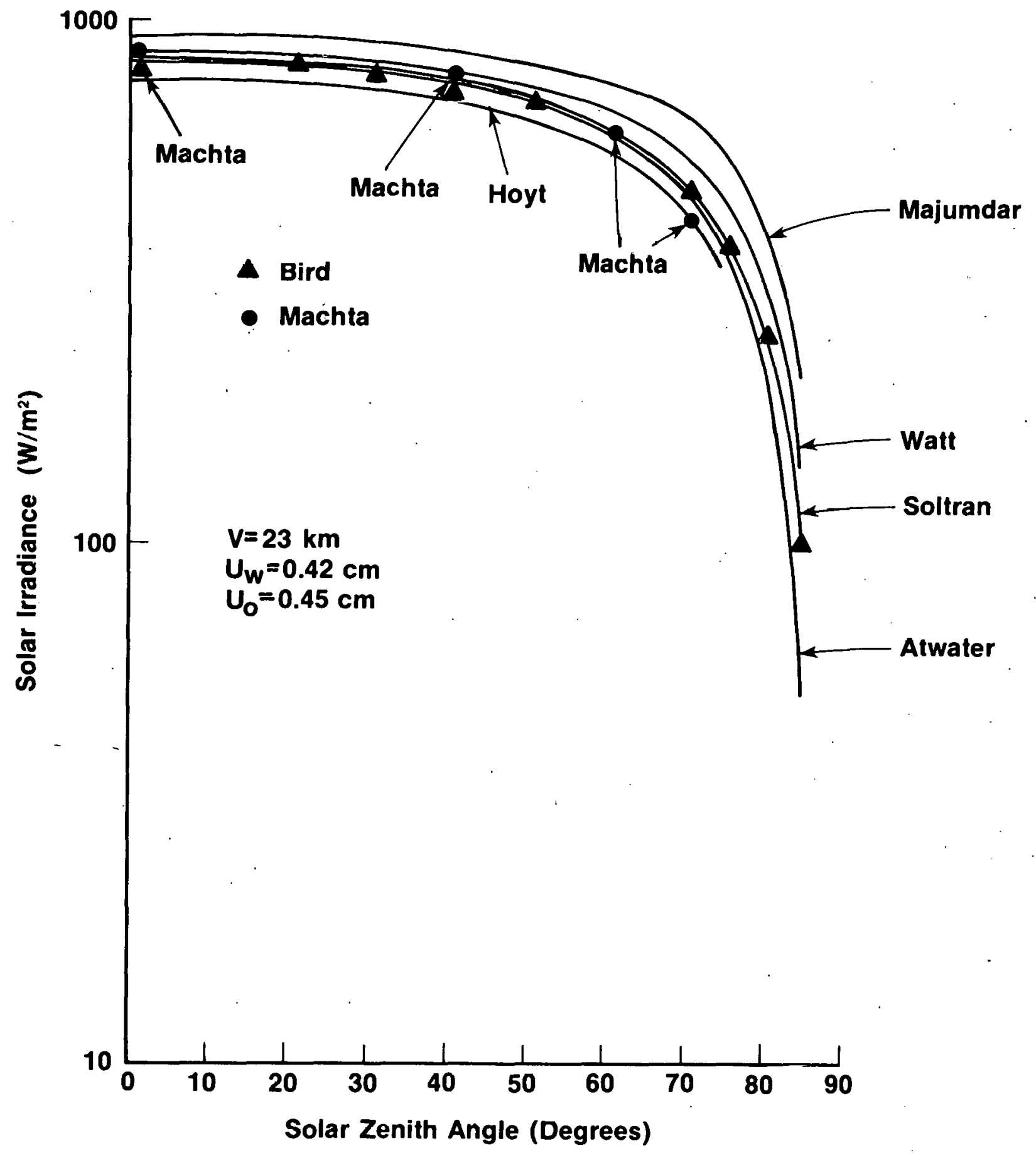

Figure 3-11. Solar Irradiance versus Solar Zenith Angle, Visibility = $23 \mathrm{~km}$ (MLS) 


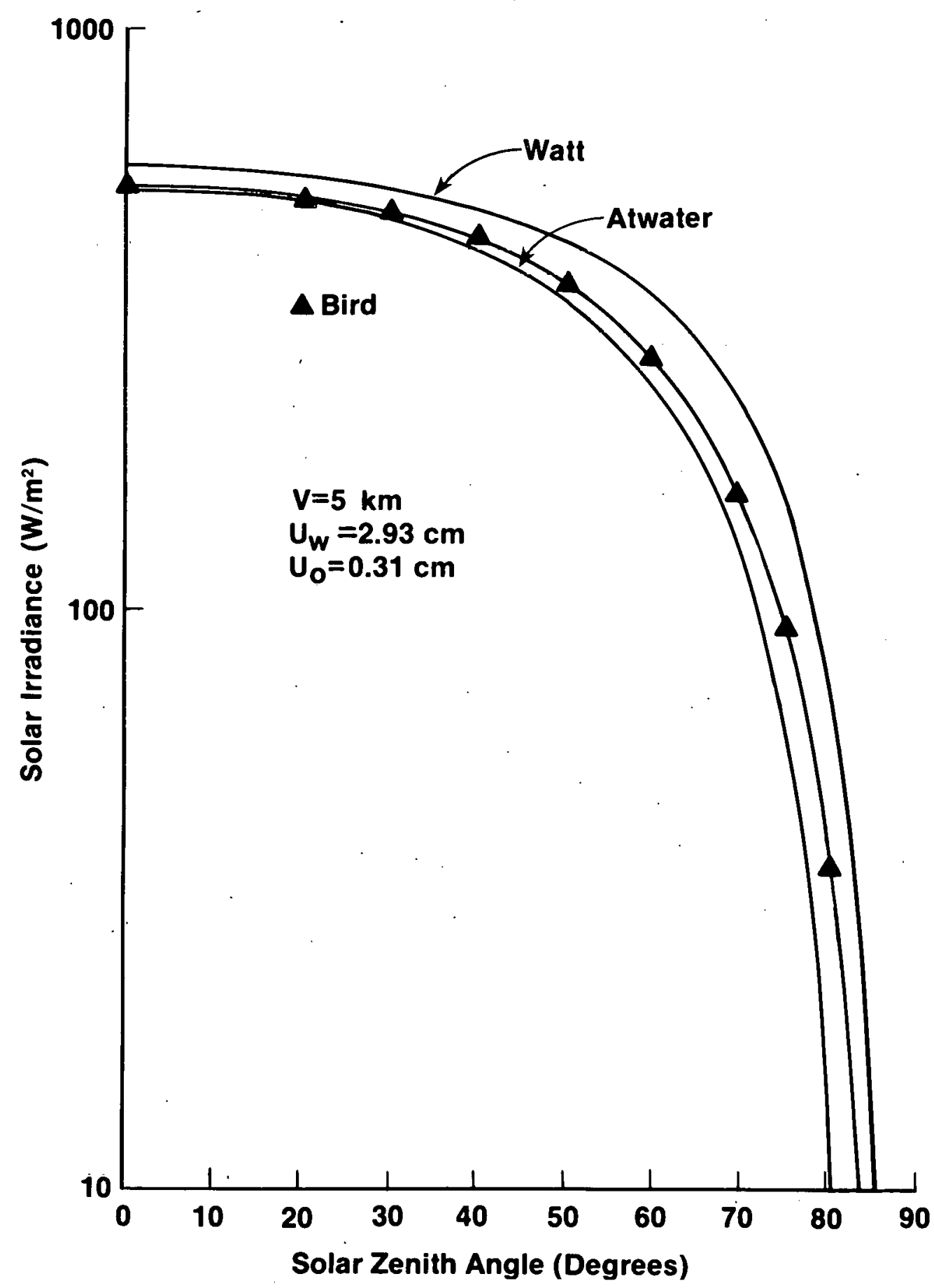

Figure 3-12. Solar Irradiance versus Solar Zenith Angle, Visibility $=5 \mathbf{~ k m}$ (MLS) 


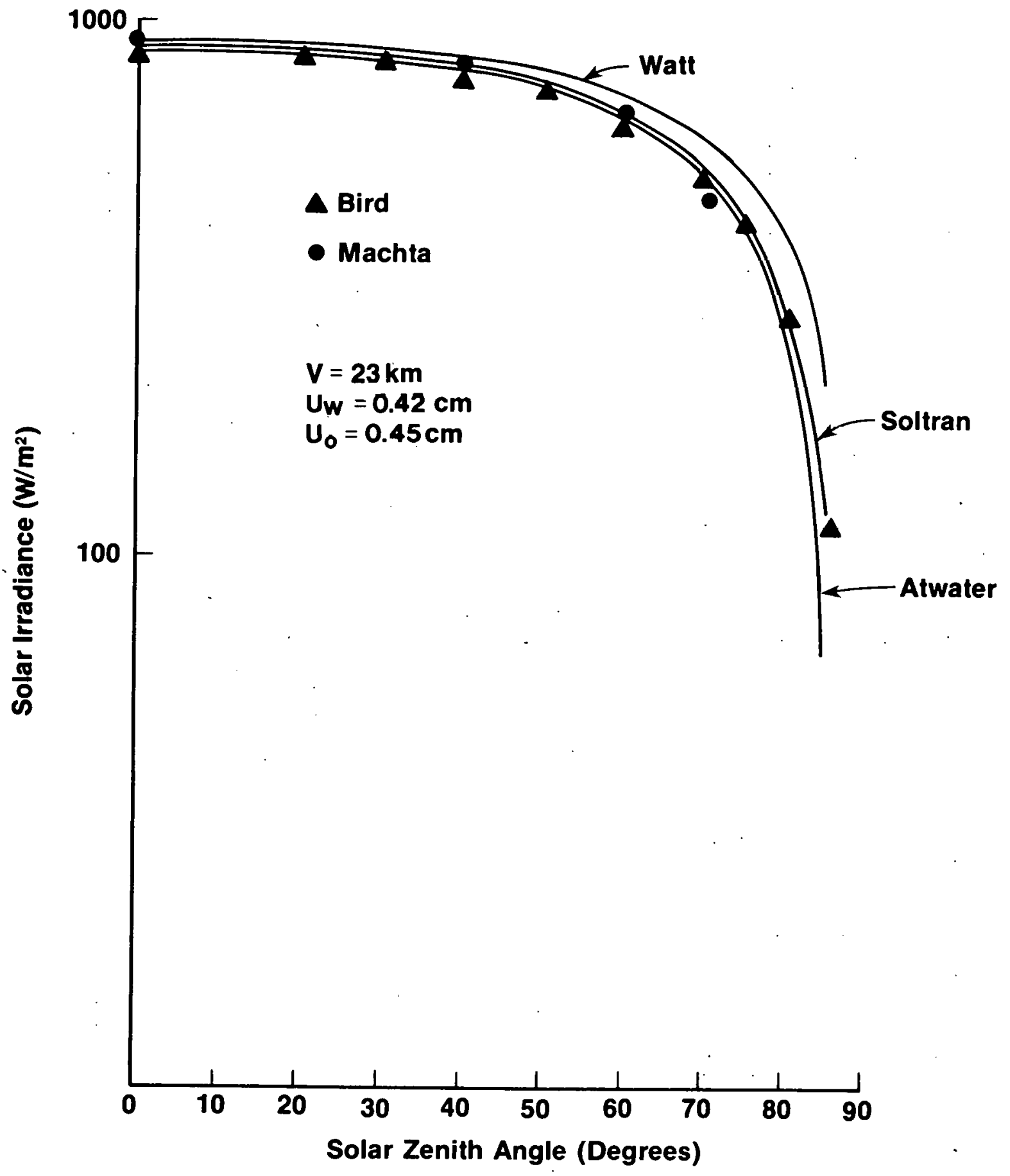

Figure 3-13. Solar Irradiance versus Solar Zenith Angle, Visibility = 23 km (SAW) 
- the atmospheric transmittance due to all molecular processes except water vapor absorption (Atwater; Watt),

- the atmospheric transmittance due to aerosols (Hoyt; Watt),

- the direct solar beam irradiance versus solar zenith angle (Machta; Hoyt; Majumdar; Watt; Atwater).

In general; two sets of atmospheric conditions were considered: midlatitude summer (MLS) and subarctic winter (SAW). The MLS conditions are characterized by a precipitation water vapor of $2.93 \mathrm{~cm}$ (high) and an ozone amount of $0.31 \mathrm{~cm}$ (10w). The SAW conditions are distinguished by a water vapor of only $0.42 \mathrm{~cm}$ (low), and an ozone amount of $0.45 \mathrm{~cm}$ (high). Within these conditions, two sets of atmospheric aerosol conditions were studied: clear (visual range $=23 \mathrm{~km}$ at sea level) and turbid (visual range $=5 \mathrm{~km}$ at sea leve1). By using these models and conditions, $a$ reasonable range of atmospheric states was considered. 
SER1* 
SECTION 4.0

\section{SUMMARY AND CONCLUSIONS}

The recently developed, rigorous, spectral solar radiation transport model (SOLTRAN) was modified to have the capability of calculating the broadband (thermal solar energy) direct solar beam irradiance. Such energy is utilized by solar thermal concentrator devices. The modifications to SOLTRAN allow the prediction of the broadband solar irradiance for various atmospheric conditions and for various slant paths (relative air mass) through the atmosphere. The atmospheric constituents considered are carbon dioxide $\left(\mathrm{CO}_{2}\right)$, oxygen $\left(\mathrm{O}_{2}\right)$, ozone $\left(\mathrm{O}_{3}\right)$, water vapor $\left(\mathrm{H}_{2} \mathrm{O}\right)$, aerosols, and the molecular scattering (Rayleigh). This modified version of SOLTRAN can be utilized to generate the intensity of the direct solar beam versus time of day for various locations and atmospheric conditions. Such information is crucial to the design and performance analyses of solar concentrator systems and central receiver systems.

After having developed the broadband-thermal version of SOLTRAN, it was then used to perform the following investigations and analyses:

- definition of the relative significance of the various atmospheric constituents to the attenuation-transmittance of the direct solar beam energy;

- comparison and evaluation of simplified models/algorithms;

- development of an improved, simplified model for solar energy.

The broadband SOLTRAN calculation delineated the relative significance of the various atmospheric constituents in the transmittance of direct solar beam energy. Aerosols appear to dominate the attenuation for a reasonable range of atmospheric conditions. Molccular scattering (Rayleigh) is next in importance, followed by water vapor absorption. These three attenuation processess-aerosol scattering, molecular scattering, and water vapor absorptionnearly coupletely determine the transmittance of the atmosphere to direct solar energy on a clear day. Attenuation caused by $\mathrm{CO}_{2}, \mathrm{O}_{2}$, and $\dot{O}_{3}$ is minor. Because aerosols and water vapor are so important in determining the available direct solar beam energy, one needs high-quality measurements of their geographic and temporal characteristics. In the absence of actual measurements of the direct beam, such measurements could be used (with a model like SOLTRAN) to assess the availability and character of the direct solar beam energy. The SERI Energy Resource Assessment Branch will determine the availability of the aerosol (turbidity) and the water vapor measurements database, their quality, their applicability to assessing direct solar beam energy, and whether improved instrumentation and techniques are required to meet the needs of solar energy applications.

The comparisons of the ozone absorptance revealed significant differences between the simplified models and SOLTRAN. The magnitude of the differences is a function of solar zenith angle and amount of ozone. In general, SOLTRAN predicts a lower absorptance due to ozone than the Hoyt, Watt, and Lacis and Hansen models. The total range of the differences is determined by the Hoyt 
(high) and SOLTRAN (low) models, being approximately $30 \%$ to $50 \%$ in absorptance. The Watt and the Lacis and Hansen models appear to give quite similar results, which fall between the Hoyt and SOLTRAN results. Although the $30 \%$ to $50 \%$ differences are certainly significant, they are not considered to be a significant source of differences in calculating the total broadband direct irradiance because the contribution of ozone to the total broadband attenuation is minor.

For low amounts of water vapor $(0.42 \mathrm{~cm})$, the comparisons of the simplified models with. SOLTRAN revealed that the Lacis and Hansen and Hoyt models gave results similar to SOLTRAN, while the McDonald and Watt models gave significantly lower values for water vapor absorptance. These differences depend on solar zenith angle, but they range from $25 \%$ to $75 \%$. For high amounts of water vapor $(2.92 \mathrm{~cm})$, the Hoyt, McDonald, Lac1s and Hansen, and SOLTRAN models yield similar results from an approximate solar zenith angle of $0^{\circ}$ to $60^{\circ}$. At greater angles the models diverge somewhat. The Watt model results in significantly lower values, by about $50 \%$, than all otler models. Again, the significance of these differences to the calculation of the broadband direct irradiance is determined by the relative significance of water vapor to the total attenuation.

The comparisons of the transmittance due to all molecular effects except water vapor revealed close agreement between the Atwater and SOLTRAN results. The Watt model gave results that were lower in transmittance, depending on solar zenith angle.

The comparison of aerosol transmittance versus solar zenith angle for the MLS conditions with turbid aerosol conditions revealed that the Watt model gave significantly higher values than the SOLTRAN model. For the SAW with clear (visual range of $23 \mathrm{~km}$ ) conditions, the Hoyt and SOLTRAN models gave similar results. The Watt model gave significantly higher transmittance values.

The cumparisons of calculated direct beam solar irradiance versus solar zenith angle were performed for the MLS conditions, with a clear atmosphere (visual range $=23 \mathrm{~km}$ at sea level) and a turbid atmosphere (visual range $=5 \mathrm{~km}$ at sea level). The comparisons for the clear atmosphere revealed that the Machta, Atwater, and SOLTRAN models agree fairly closely; the Huyt model results in lower values of direct irradiance, but they are within approximately $10 \%$ of the SnITRAN/Atwator/Machea values. However, at large solar zenith angles (greater than $70^{\circ}$ ) the models begin to diverge significantly. The Watt model agrees favorably with the SOLTRAN/Atwaler/Machta values up to a solar zenith angle of about $70^{\circ}$; at greater anglec the Watt mudel predicts siguificantly higher values. The Majumdar model gives much higher values of direct irradiance versus solar zenith angle than all other models, by as much as $20 \%$. The comparisons for a turbid atmosphere could only be performed for the Watt, Atwater, and SOLTRAN models due to limitations in the other models to clear conditions. It was shown that the Atwater aud SOLTRAN model agree favorably to a zenith angle of $70^{\circ}$. The Watt model predicts significantly higher values, especially past zenith angles of $50^{\circ}$. Below zenith angles of $50^{\circ}$, the Watt values are within about $10 \%$ of the SolTRAN/Atwater results. Comparisons were also performed for the SAW atmosphere with clear conditions. This again revealed agreement between the SOLTRAN and Atwater models, and characteristically, that the watt model tends to predict high values. 
However, for these SAW and clear conditions, the Watt model is in fairly good agreement to zenith angles of about $70^{\circ}$.

Finally, the rigorous SOLTRAN results were used to develop an improved, simplified model for predicting the direct solar beam energy as a function of atmospheric conditions and solar zenith angle. The improvements consist of higher accuracy (as compared to the SOLTRAN results) and the ability to handle readily available, specific inputs to characterize the atmospheric water vapor and aerosols. Mathematical formulations were derived by comparison with SOLTRAN results for the atmospheric transmittance components of molecular (Rayleigh) scattering, ozone absorption, uniformly mixed gas $\left(\mathrm{CO}_{2}\right.$ and $\left.\mathrm{O}_{2}\right)$ absorption, water vapor absorption; and aerosol scattering and absorption, as functions of relative air mass (solar zenith angle). The inputs to the model (Bird) are surface pressure, precipitable ozone, precipitable water vapor, and aerosol turbidity at $0.38 \mathrm{\mu m}$ and at $0.500 \mathrm{\mu m}$. Thus the Bird model allows the calculation of the direct solar beam irradiance as a function of avallable atmospheric parameters, which properly consider the significant water vapor and aerosol constituents.

The absolute accuracy of the Bird, SOLTRAN, and other models can be determined only by comparisons with actual measurements of the direct solar beam irradiance and measurements of the atmospheric inputs. Unfortunately, such comparisons and measurements have been lacking in the past in the visible region [46-50]; when done, they will probably result in improvements in the SOLTRAN and simplified models. The SERI Energy Resource Assessment Branch and the Solar Energy Meteorological Research and Training sites (university research programs sponsored by DOE to collect insolation and meteorological research data at eight locations within the United States) will be collecting such data and performing research that will greatly advance the state of knowledge concerning the atmospheric influences on the direct solar beam irradiance. Consequently, this will lead to improved prediction models for the direct solar beam irradiance and improved design and predictions of solar energy conversion devices. 


\section{Sझरㄴ.}


SECTION 5.0

REFERENCES

1. Selby, J. E. A.; Kneizys, F. X.; Chetwynd, J. H.; McClatchey, R. A. Atmospheric Transmittance/Radiance: Computer Code LOWTRAN 4. AFGL-TR78-0053; 1978.

2. Selby, J. E. A.; Shettle, E. P.; McClatchey, R. A. Atmospheric Transmittance from 0.25 to $28.5 \mathrm{~m}$ : Supplement LOWTRAN 3B. AFGL-TR-76-0258; 1976.

3. Selby, J. E. A.; McClatchey, R. A. Atmospheric Transmittance from 0.25 to $28.5 \mu \mathrm{m}$ : Computer code LOWTRAN 3. AFCRL-TR-75-0255; 197.

4. Thekaekara, M. P. "Extraterrestrial Spectral Irradiance." The Extraterrestrial Solar Spectrum, A. J. Drummond and M. P. Thekaekara, eds. Mount Prospect: Institute of Environmental Sciences; pp. 71-133; 1973.

5. McClatchey, R. A.; Fenn, R. W.; Selby, J. E. A.; Volz, F. E.; - Garing, J. S. Optical Properties of the Atmosphere (Third Edition). AFCRL-72-0497; 1972 .

6. Atwater, M. A.; Ball, J. T. "A Numerical Solar Radiation Model Based on Standard Meteorological Observations." Solar Energy. Vol. 21: pp. $163-170 ; 1978$.

7. Atwater, M. A.; Brown, P. S. "Numerical Computations of the Latitudinal Variation of Solar Radiation for an Atmosphere of Varying Opacity." J. Applied Meteorology. Vo1. 13: pp. 289-297; 1974.

8. Paltridge, G. W.; Platt, C. M. R. Radiative Processes in Meteorology and Climatology. New York: Elsevier; 1976.

9. Kondratyev, K. YA. Radiation in the Atmosphere. New York: Academic Press; 1969.

10. McDonald, J. E. "Direct Absorption of Solar Radiation by Atmospheric Water Vapor." J. Meteorology. Vol. 17: pp. 319-328; 1960.

11. Hoyt, D. V. "A Model for the Calculation of Solar Global Insolation." Solar Energy. Vol. 21: pp. 27-35; 1978.

12. Lacis, A. L.; Hansen, J. E. "A Parameterization for the Absorption of Solar Radiation in the Earth's Atmosphere." J. Atmospheric Science. Vo1. 31: pp. 118-133; 1974.

13. Machta, L. Workbook for Approximate Calibration of Solar Radlation Sensors. Silver Spring, MD: Nationa1 nceanic and Atmospheric Administration; TM-ERL-ARL-70; 1978. 
14. Braslau, N.; Dave, J. V. Effect of Aerosols on the Transfer of Solar Energy Through Realistic Model Atmospheres. Palo Alto, CA: IBM Research; RC4114; 1972 .

15. The American Society of Heating, Refrigeration and Air Conditioning Engineers. ASHRAE HANDBOOK OF FUNDAMENTALS. $1972 \mathrm{ed.}$

16. Jordan, R. C.; Liu, B. Y. H., eds. Applications of Solar Energy for Heating and Cooling of Buildings. ASHRAE-GRP-170; 1.977 .

17. Hulstrom, R. L. Insolation Models, Data and Algorithms. Golden, CO: Solar Energy Research Institute; SERI/TR-36-11n; 1978.

18. Watt, D. On the Natule and Dlscribution of Solar Radiation. U. S. Department of Energy; HCP/T2552-01; 1978.

19. Moon, P. "Proposed Standard Solar-Radiation Curves for Engineering Use." J. Franklin Institute. Vol. 230: pp. 583-617; 1940.

20. Majumdar, N. C.; Mathur, B. L.; Kaushik, S. B. "Prediction of Direct Solar Radiation for Low Atmospheric Turbidity." Solar Energy. Vo1. 13: pp. 383-394; 1972.

21. Kasten, F. "A New Table and Approximate Formula for Relative Optical Air Mass." Arch. Meteoral. Geophys. Bioklimatal. Series B, Vol. 14 (No. 2): pp. 206-223; 1966.

22. Laviès, A. D.; Hay, J. E. "Calculation of the Solar Radiation Incident on a Horizontal Surface." Proceedings, First Canadian Solar Radiation Data Workshop. Apri1 17-19, 1978. Canadian Atmospheric Envirnnment Service; 1979.

23. Burch, D. E. Semi-Annual Technical Report, Investigation of the $\mathrm{Ab}-$ sorption of Infrared Radiation by Atmospheric Gases. Philco Ford Corp.; Aeronutronic Report U 4784; Contract No. F19628-69-C-0263; 1970.

24. Burch, D. E.; Gryvnak, D. A. Absorption by $\mathrm{H}_{2} \mathrm{O}$ Between 5045 and $14,485 \mathrm{~cm}^{-1}$ (0.69 to $1.98 \mathrm{\mu m}$ Region). Aeronutronic Report U-3704; 1966 .

25. Burch, D. E.; Gryvnak, D. A. Strengths, Widths and Shapes of the Oxygen Lines Near 7600 Angstroms. Aeronutronic Report U-4076; 1967.

26. Burch, D. E.; Gryvnak, D. A.; Patty, R. R. Absorption by $\mathrm{CO}_{2}$ Between

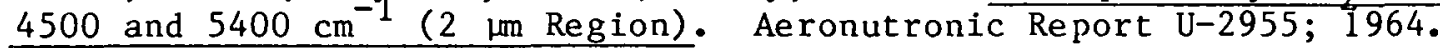

27. Burch, D. E.; Gryvnak, D. A.; Patty, R. R. Absorption by $\mathrm{CO}_{2}$ Between 6600 and $7125 \mathrm{~cm}^{-1}$ (1.4 um Reg1on). Aeronutronic Report U-3127;1965a.

28. Burch, D. E.; Gryvnak, D. A.; Patty, R. R. Absorption by $\mathrm{CO}_{2}$ Between 8000 and $10,000 \mathrm{~cm}^{-1}$ (1, to 1.25 mon Region). Aeronutronic Report U-3200;

$1965 \mathrm{~b}$. 
22. Burch, D. E.; Gryvnak, D. A.; Patty, R. R. Absorption by $\mathrm{CO}_{2}$ Between 5400 and $6600 \mathrm{~cm}^{-1}$ (1.6 $\mu \mathrm{m}$ Region). Aeronutronic Report U-3201; $1965 \mathrm{c}$.

30. Burch, D. E.; Gryvnak, D. A.; Patty, R. R. Absorption by $\mathrm{H}_{2} \mathrm{O}$ Between 2800 and $4500 \mathrm{~cm}^{-1}$ (2.7 $\mathrm{m}$ Region). Aeronutronic Report U-3202; $1965 \mathrm{~d}$.

31. Burch, D. E.; Gryvnak, D. A.; Patty, R. R. Absorption by $\mathrm{CO}_{2}$ Between 7125 and $8000 \mathrm{~cm}^{-1}$ (1.25 to $1.4 \mathrm{~lm}$ Region). Aeronutronic Report U-3930; 1967.

32. Burch, D. E.; Gryvnak, D. A.; Patty, R. R. Absorption by $\mathrm{CO}_{2}$ Between 3100 and $4100 \mathrm{~cm}^{-1}(2.44$ to 3.22 in Region). Aeronutronic Report U-4132; 1968.

33. Burch, D. E.; Gryvnak, D. A.; Singeleton, . E. B.; France, W. F.; Williams, D. Infrared Absorption by Carbon Dioxide, Water Vapor and Minor Atmospheric Constituents. AFCRL; Research. Contract AF19 (604)2633; Ohio State University; 1962.

34. McClatchey, R. A.; Benedict, W. S.; Clough, S. A.; Burch, D. E.; Calfee; R. F.; Fox, K.; Rothman, L. S.; Garing, J. S. AFCRL Atmospheric Line Parauleter Compilation. AFCRL-TR-73-0096; 1973.

35. Fowle, F. E. "The Transparency of Aqueous Vapor." Astrophysics. J. Vol. 42: pp. 394-411; 1915.

36. Yamamoto, G. "Direct Absorption of Solar Radiation by Atmospheric Water Vapor, Carbon Dioxide and Molecular Oxygen." J. Atmospheric Science. Vol. 19: pp. 182-188; 1962.

37. Howard, J. N.; Burch, D. E.; Williams, D. "Infrared Transmission of Synthetic Atmospheres, Parts I-V." J. Optical Society of America. Vo1. 46: pp. 186-190, 237-241, 242-245, 334-338, 452-455; 1956.

38. Valley, S. L., ed. "Solar Electromagnetic Radiation." Chapter 16 in Handbook of Geophysics and Space Environments. Air Force CambridgeResearch Laboratories; 1965.

39. Wulf, O. R. "The Determination of Ozone by Spectrobolometric Measurements." Smithsonian Miscellaneous Collection. Vol. 85 (No. 9): p. 9; 1931 .

40. Lauchli, A. "Zur Absorption der Ultravioleten Strahlung im Ozon." Zs. F. Phys. p. 92; 1929.

41. Manabe, S.; Strickler, R. F. "Thermal Equilibrium of the Atmosphere with Convective Adjustment." J. Atmospheric Science. Vol. 21: pp. 361-385; 1964 .

42. Vigroux, E, "Contributions a l'etude Experimentale de l'absorption de 1.'nzone." Ann. de Physique. Vol. 8: pp. 709-762; 1953. 
43. Inn, E. C. Y.; Tanaka, Y. "Absorption Coefficient of Ozone in the Ultra-Violet and Visible Regions." J. Optical Society American. Vo1. 43: pp. 870-873; 1953.

44. Howard, J. N.; Burch, D. E.; Williams, D. Near-Infrared Transmission Through Synthetic Atmospheres. AFCRC-TR-55-2 $\overline{13 ; 1955 .}$

45. Burch, D. E.; Gryvnak, D.; Williams, D. The Infrared Absorption by Carbon Dioxide. Ohio State University Research Foundation; Report on Project 778; 1960 .

46. Shettle, E. P.; Fenn, R. W. "Models of the Atmospheric Aerosols and Their optical Properties." Proceeding of AGARD Conference No. 183, Optical Propagation in the Atmosphere. pp. 2.1-2.16, presented at the Electromagnetic Wave Propagation Panel Sympoșiu!n, Lyngby, Denmark; 27-31 October 1975.

47. Roberts, R. E.; Selby, J. E. A.; Biberman, L. M. "Infrared Continuum Absorption by. Atmospheric Water Vapor in the 8-12 un Window." Applled Optics. Vol. 14: p. 2085; 1976.

48. Haught, K. M.; Corday, D. M. "Long-Path High-Resolution Atmospheric Transmission Measurements: Comparison with LOWTRAN 3B Predictions." Applied Optics. Vol. 17: pp. 2668-2670; 1978.

49. McClatchey, R. A.; Kneizys, F. X. "Long-Path High-Resolution Atmospheric Transmission Measurements: Comparison with LOWTRAN 3B Predictions; Comments." Applied Optics. Vol. 18: pp. 592-593; 1979.

50. Haught, K. M.; Cordray, D. M. "Long-Path High-Resolution Atmospheric Transmission Measurements: Comparisons with T.OWTRAN 3B Predictions; Reply to Comments." Applied Optics. Vol. 18; p. 593; 1979. 


\section{APPENDIX}

\section{TABULATED MODEL DATA}

A compilation of computer outputs for the Atwater and Ball, Watt, Bird, Lacis and Hansen, Majumdar, and the Hoyt models are presented. The atmospheric models used were the Midlatitude Summer (MLS) and the Subarctic Winter (SAW) models with $23 \mathrm{~km}$ and $5 \mathrm{~km}$ sea level visibilities for each model. The direct normal irradiance (IDN) is not included for the Bird models since it was given previously in Tables $2-2$ and $2-3$. The SOLTRAN output is also 1isted in Tables 2-2 and 2-3. The IDN is not given in the Hoyt model, because parts of the calculation that required look-up tables were done on a hand calculator.

For the MS model, $2.93 \mathrm{~cm}$ of $\mathrm{H}_{2} \mathrm{O}$ and $0.31 \mathrm{~cm}$ of $\mathrm{O}_{3}$ was used. The SAW used $0.42 \mathrm{~cm}$ of $\mathrm{Il}_{2} \mathrm{O}$ and $0.45 \mathrm{~cm}$ of $\mathrm{O}_{3}$. The turbidity at 0.5 and $0.38 \mu \mathrm{m}$ wavelength was 0.2733 and 0.3469 , respectively, for $\mathrm{V}=23 \mathrm{~km}$; and 0.9243 and 1.1727 , respectively, for $\mathrm{V}=5 \mathrm{~km}$. In all cases, the incident extraterrestrial irradiance was $1353 \mathrm{~W} / \mathrm{m}^{2}$. 
Table A-1. Tabulated Data for the Midlatitude Summer Atmosphere $(V=23 \mathrm{~km})$ for Several Models

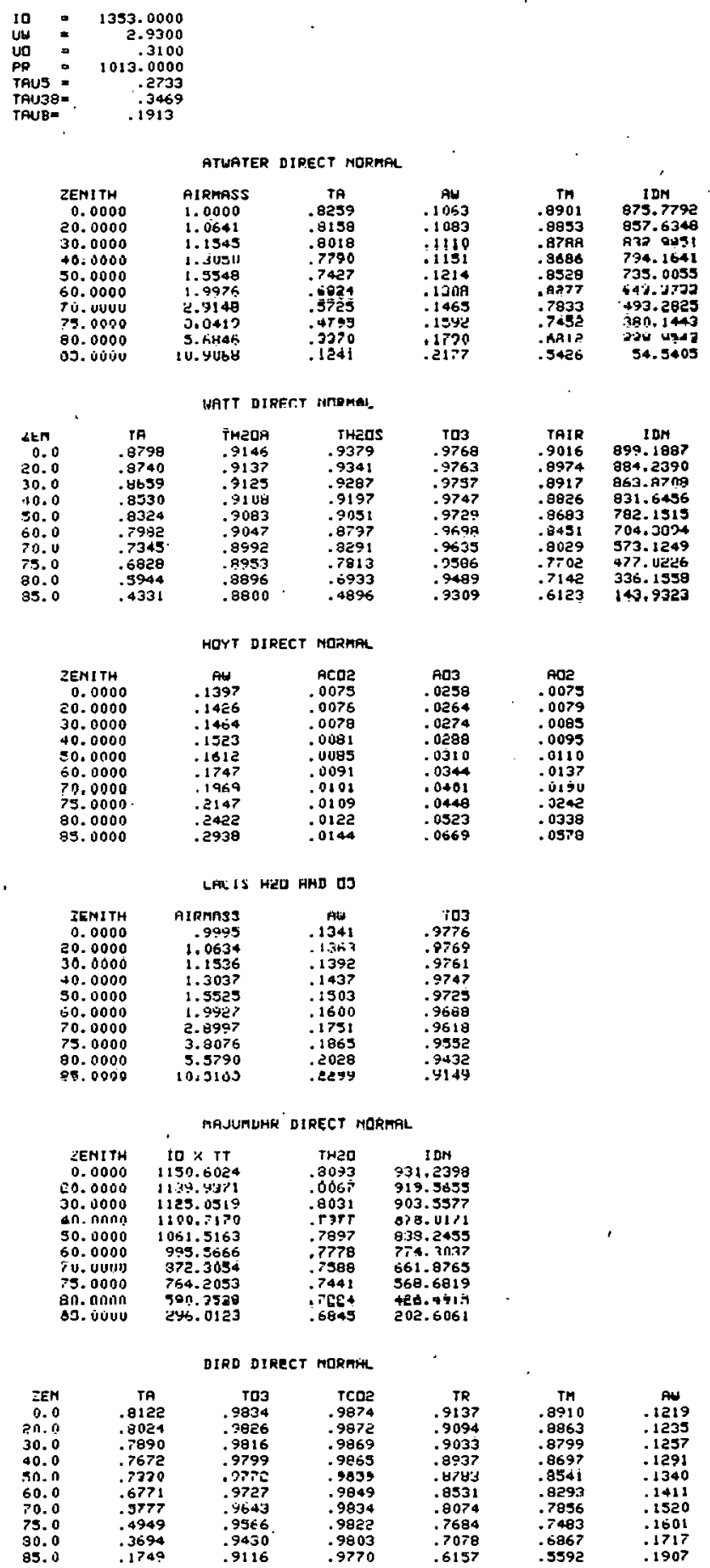




\section{Table A- 2. Tabulated Data for the Midlatitude Summer Atmosphere $(V=5 \mathbf{~ k m})$ for Several Models.}

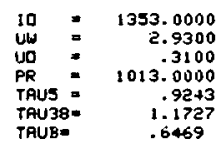

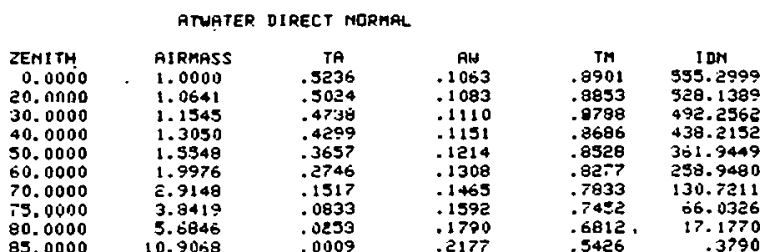

WATT DIPECT MDPMAL
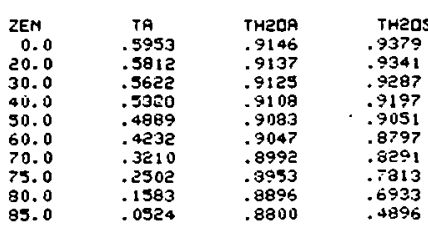

.9146
.9137

.9341

.9129

.9108

.9197
.9051
.0797

9047

.8992

.8797
.8291

.02913
.6933

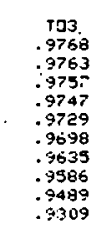

TAIR

$.9016 \quad 508.4533$

.8974

588.0320

560.8678

519.4331

373.4774

230.4940

174.8369
89.5032
17.4248

HOYT DIPEC.T MORMAL

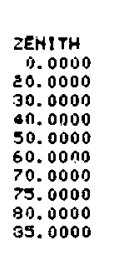

\begin{tabular}{|c|c|c|c|}
\hline $\begin{array}{r}\text { Aw } \\
.1397 \\
.1426 \\
.1464 \\
.1523 \\
.1612 \\
.1747 \\
.1969 \\
.2147 \\
.2422 \\
.2938\end{array}$ & $\begin{array}{r}n c 0 a \\
.0075 \\
.0076 \\
.0078 \\
.0081 \\
.01885 \\
.0091 \\
.0101 \\
.0109 \\
0122 \\
.0144\end{array}$ & $\begin{array}{l}\text { An3 } \\
.0258 \\
.0264 \\
.0274 \\
.0288 \\
.0310 \\
.0344 \\
.0401 \\
.0448 \\
.0523 \\
.0669\end{array}$ & $\begin{array}{l}\text { A02 } \\
.0075 \\
.0079 \\
.0085 \\
.0095 \\
.01118 \\
.0137 \\
.0190 \\
.0242 \\
.0338 \\
.0578\end{array}$ \\
\hline
\end{tabular}

2ENITH

0.0000
20.0000

30.0000
40.0000

40.0000
$\$ 0.0000$

50.0000

70.0000
75.0000

80.0000
85.0000

LACIS HEO AND OJ
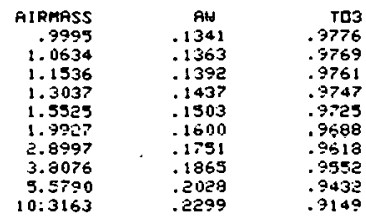

HAJUMDRR DIRECT MTOMAI

aEMtTH

$10 \times 17$
1150.0024
1139.9371
1125.051 .9
1100.7170
1061.5153
995.5666
872.3054
764.2053
590.3528
39.0123

THEO
8033

0.0000
20.0000

30.0000

410.0000

60.0000

70.0090

80.0000

85.0000

BIRD DIPECT MCPMAL

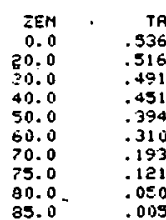

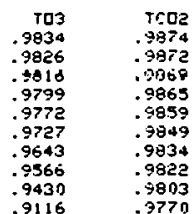
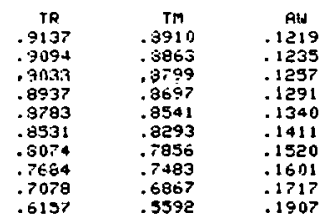


\section{Table A-3. Tabulated Data for the Subarctic Winter Atmosphere $(V=23 \mathrm{~km})$ for Several Models}
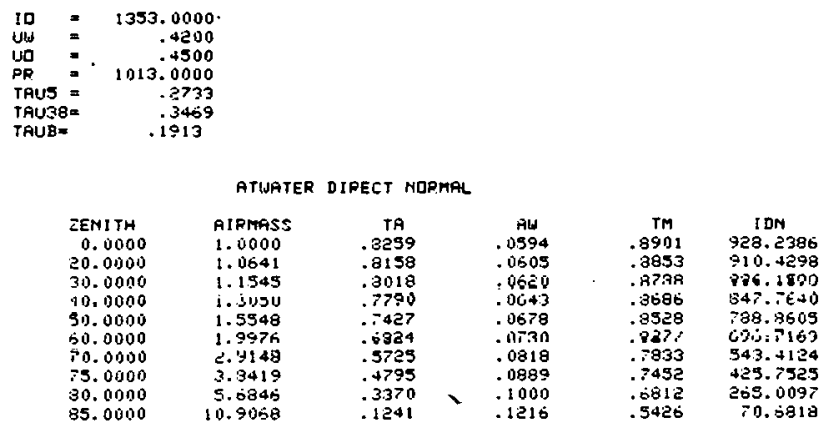

IUATT DIRECT MERMAL.

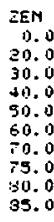

THEDA

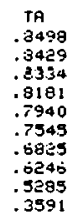

$.920 R$
.9424
.9415

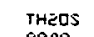

THEOS
.9909
.99013
9804

703
.9736
.9730
972

.4981

- 933

.9325

.927
.9231

.9858

.9735
.9652
9468

.9706

.9581

.9944

.9336

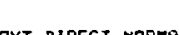

ZENT TH

0.0000
20.00000

30.0010

+0. finon

Sh. 0100

50.0000
70.0000

s. 00000

35.0000

MOYT JIRECT NOPMTH

And 0

.0727
.0743
.0754

.0797

.0047

init5

.1299
.1987

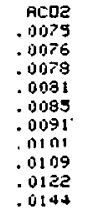

1003
.0301
.0309
.0350

.00309
.0320

.0037
.0352

.04101
.948

.0521

.0508

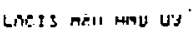

ZENITH

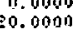

30.001010
+0.01000

50.0000

50.0000

20.0000

75.0000

Bi. 0 inon

PIPMAss

1. $\begin{array}{r}075 \\ 1.935\end{array}$

1.3035

1. 5925

3.3997

5. 5 ?90

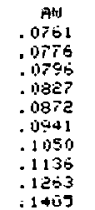

IU⿺⿻一𠃋火

9754
-9715
.9590

उ०डs?

.9524
.9518

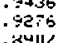

MP_IIJMDAR DIPECT MLRMAL

IENITH

$10 \mathrm{KTT}$

0.0000

20.

40.0000

50.0940

50.0000

io. 00000

80.00100

hias. 0912

1051.5163

Pas. 5606

3.2. 3054

59!. 3isa

$\begin{array}{cc}\text { THED } & \text { IDN } \\ .3780 & 1010.1838\end{array}$

13732 ;\%8.1581

.9738
.0701

.0642
.3567

.3567
.3438

eio.j1es

.7187

BLFD DIRECT RICPMAL

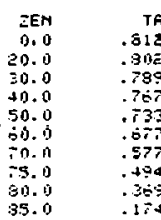

103
.4783
.773
.7759
.9737
.9708
.9644
.7534
.0434
.3256
.0948

TC02
.9874
.5978
.9969
.9365
.2059
.9849
.9644
.9622
.9903
.9770

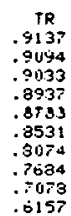
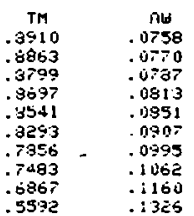


\section{Table A-4. Tabulated Data for the Subarctic. Winter Atmosphere [ $\mathrm{V}=\mathbf{5} \mathbf{~ k m}$ ] for Several Models}
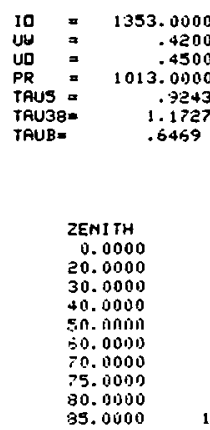

HTHATER DIRECT ADRRAL
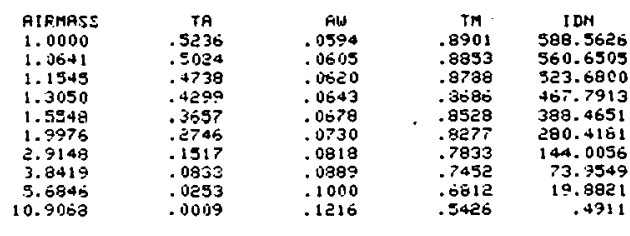

WATT DIRECT MORMAL

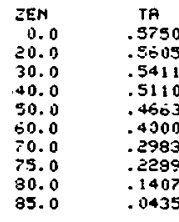

THEOA
.9024

.9424
.9415
$.9+114$

.5386

$\because 9361$

.

$T H 205$
.99199
.990 .3
.9894
.9891
.9858
.9810
.9735
.9652
.9488
.9027

103
.9736
.9730

.9730
.9721
.9706

.9691

.9636

.9544
.94736

.9336

HOYT DIPECT NDRMAL

ZENTTH
0.0000
20.0000

$20.0001)$
30.0000

+10.0000
50.0000

sc. 0000

79.00001

80.0000

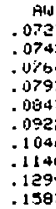

ACO2
.0075
.0070
01078
.0081

.01078
.0081
.0089

.0085

.0091

.0108
.0100
.0132

.0122
.0144

003
.0301
.0309
.0320
.0337
.0362
.0401
.0467
.0521
0.0601
.0775

0075

0079

.0085

.0119

.0190

.0578

LACIS HEO AND 03

ZEMTH
0.0010
80.0000

20.0000
30.0000

40.0000
50,0000

50.0000
50.0000

70.0000

30.0000

RIRMASS

.9999
1.0634

1.0534
1.1536
1.3037

1.3507
1.5525
1.5925

i. 1.5927

5. 3997

5.3790
9.3153

24
.0761
0726

.0776

.0927
.0872
.0941

.094

MPJUMDRR DIRECT MLPMAL

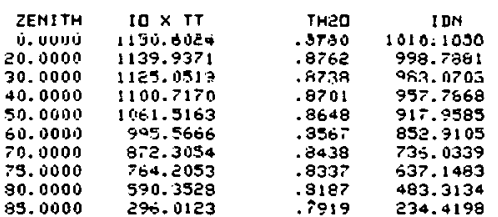

85.0000

BIRD DIRECT NAPKAL

$\begin{array}{rr}\text { ZEN } & \text { TA } \\ 0.0 & .526 \\ 20.0 & .516 \\ 30.0 & .491 \\ 40.0 & .451 \\ 30.0 & .394 \\ 60.0 & .310 \\ 70.0 & .593 \\ 75.0 & .121 \\ 80.0 & .0509 \\ 85.0 & .005\end{array}$

$$
\begin{array}{r}
r 03 \\
.9783 \\
.9773 \\
.9759 \\
.5737 \\
.9702 \\
.9644 \\
.5534 \\
.9434 \\
.9256 \\
.98+9
\end{array}
$$
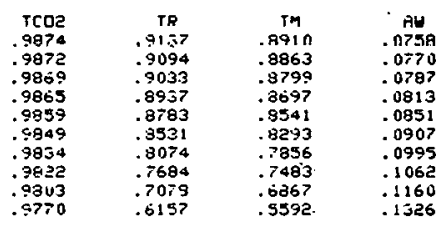


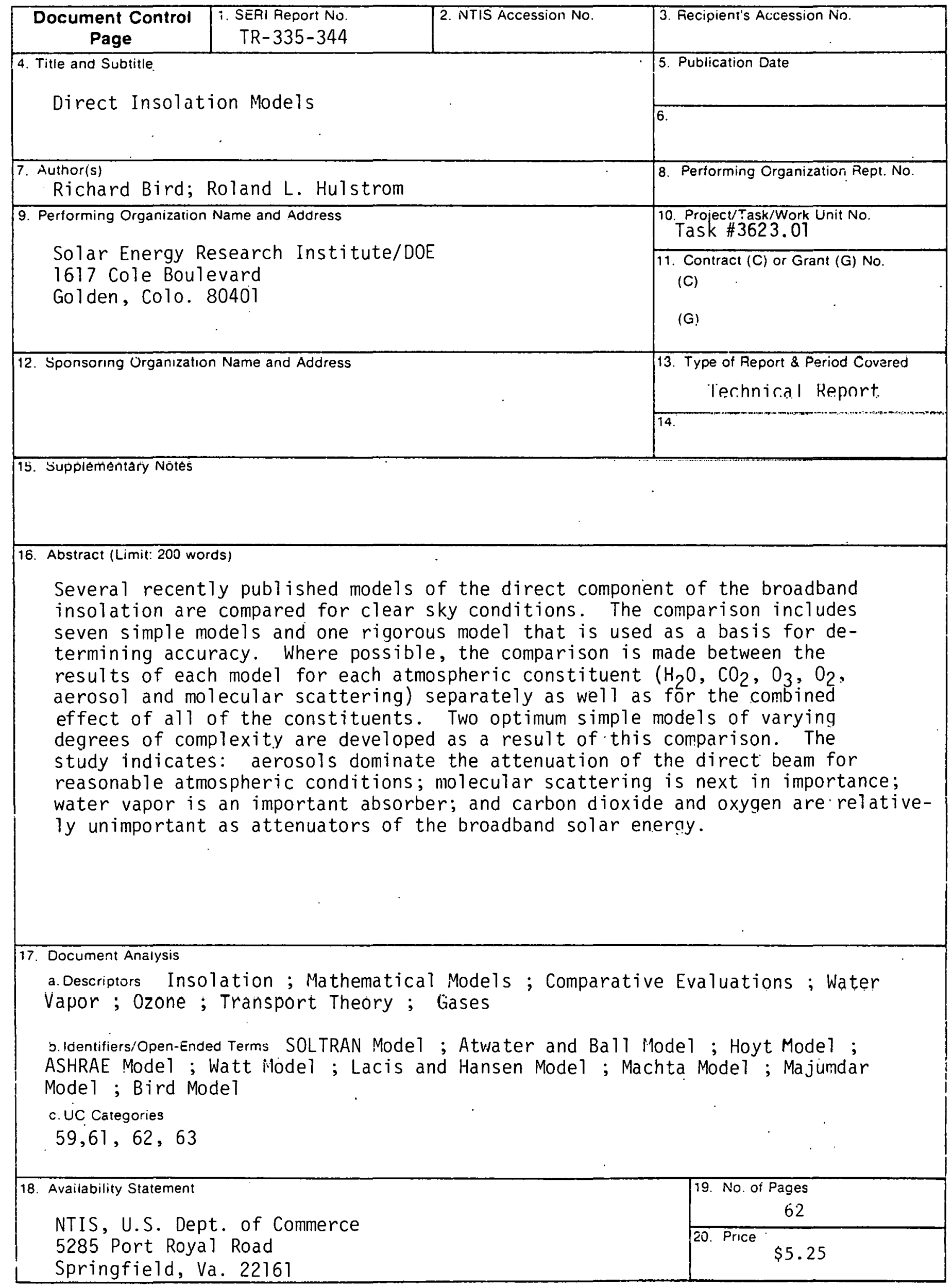

